\title{
The Interglomerular Circuit Potently Inhibits Olfactory Bulb Output Neurons by Both Direct and Indirect Pathways
}

\author{
(DShaolin Liu, Adam C. Puche, and Michael T. Shipley \\ Department of Anatomy and Neurobiology, Program in Neurosciences, University of Maryland School of Medicine, Baltimore, Maryland 21042
}

Sensory processing shapes our perception. In mammals, odor information is encoded by combinatorial activity patterns of olfactory bulb (OB) glomeruli. Glomeruli are richly interconnected by short axon cells (SACs), which form the interglomerular circuit (IGC). It is unclear how the IGC impacts $\mathrm{OB}$ output to downstream neural circuits. We combined in vitro and in vivo electrophysiology with optogenetics in mice and found the following: (1) the IGC potently and monosynaptically inhibits the OB output neurons mitral/tufted cells (MTCs) by GABA release from SACs: (2) gap junction-mediated electrical coupling is strong for the SAC $\rightarrow$ MTC synapse, but negligible for the $\mathrm{SAC} \rightarrow$ ETC synapse; (3) brief IGC-mediated inhibition is temporally prolonged by the intrinsic properties of MTCs; and (4) sniff frequency IGC activation in vivo generates persistent MTC inhibition. These findings suggest that the temporal sequence of glomerular activation by sensory input determines which stimulus features are transmitted to downstream olfactory networks and those filtered by lateral inhibition.

Key words: electrical coupling; GABA; interglomerular circuit; intrinsic properties; monosynaptic inhibition; olfactory bulb

\section{Significance Statement}

Odor identity is encoded by combinatorial patterns of activated glomeruli, the initial signal transformation site of the olfactory system. Lateral circuit processing among activated glomeruli modulates olfactory signal transformation before transmission to higher brain centers. Using a combination of in vitro and in vivo optogenetics, this work demonstrates that interglomerular circuitry produces potent inhibition of olfactory bulb output neurons via direct chemical and electrical synapses as well as by indirect pathways. The direct inhibitory synaptic input engages mitral cell intrinsic membrane properties to generate inhibition that outlasts the initial synaptic action.

\section{Introduction}

Appropriate behavioral responses to environmental stimuli require precise identification and timing of sensory signals. In the mammalian olfactory system, odor information is transduced into neural signals by olfactory receptors (ORs) expressed by olfactory sensory neurons (OSNs) (Jones and Reed, 1989). Each OSN expresses only one type of ORs out of a repertoire of $\sim 1100$ OR genes. The axons of OSNs with the same OR converge on a pair of glomeruli in each olfactory bulb (OB) (Ressler et al., 1994; Vassar et al., 1994; Mombaerts et al., 1996; Belluscio et al., 2002) where they form synaptic connections with the second-order

\footnotetext{
Received June 1, 2016; revised July 7, 2016; accepted July 28, 2016.

Author contributions:S.L., A.C.P., and M.T.S. designed research; S.L. performed research; S.L. analyzed data; S.L., A.C.P., and M.T.S. wrote the paper.

This work was supported by National Institutes of Health Grants DC005676, DC010915, and DC014447.

The authors declare no competing financial interests.

Correspondence should be addressed to Dr. Shaolin Liu, Department of Anatomy and Neurobiology, Pro-

gram in Neuroscience, University of Maryland School of Medicine, 20 Penn Street, Baltimore, MD 21042.

E-mail: sliu@som.umaryland.edu.

D0I:10.1523/JNEUROSCI.1763-16.2016

Copyright $\odot 2016$ the authors $\quad 0270-6474 / 16 / 369604-14 \$ 15.00 / 0$
}

neurons, including local glomerular interneurons (Hayar et al., 2004a; De Saint Jan et al., 2009; Shao et al., 2009; Kiyokage et al., 2010; Gire et al., 2012) and apical dendrites of mitral and tufted cells (MTCs) (Najac et al., 2011), the principal OB output neurons. One odorant typically differentially activates multiple types of ORs, OSNs, and their targeted glomeruli. Odor identity is encoded by specific combinations of activated glomeruli (Johnson et al., 1998; Mori et al., 1999; Johnson and Leon, 2007). However, multiple lines of evidence support that activated glomeruli interact before the transfer of information to higher brain regions. In the Drosophila antennal lobe, activating a single glomerulus with one odor elicits activity of inhibitory local interneurons in all glomeruli (Hong and Wilson, 2015). In the mouse olfactory bulb "short axon cells" (SACs) form the interglomerular circuit (IGC) that interlinks neighboring and distant glomeruli (Aungst et al., 2003; Kosaka and Kosaka, 2008; Kiyokage et al., 2010). IGC acts on glomerular targets by corelease of the inhibitory transmitter, GABA, and the modulatory transmitter, dopamine (DA) (Borisovska et al., 2013; Liu et al., 2013).

Previous in vivo studies reported that the IGC mediates $\mathrm{GABA}_{\mathrm{B}}$ receptor-mediated presynaptic inhibition of olfactory 
nerve (ON) terminals (McGann et al., 2005; Vucinić et al., 2006). However, it remains unclear how the IGC acts on postsynaptic glomerular targets to shape their output to downstream networks. Selective activation of the IGC by optogenetic targeting of SACs triggers an inhibition-excitation sequence in external tufted cells (ETCs) (Liu et al., 2013), a subpopulation of glomerular excitatory interneurons that receive direct OSN input (Hayar et al., 2004b; Liu and Shipley, 2008a) and monosynaptically excite MTCs (De Saint Jan et al., 2009; Gire et al., 2012), vast majority of SACs and periglomerular cells (PGCs) (Hayar et al., 2004a; Shao et al., 2009; Kiyokage et al., 2010). GABAergic PGCs provide strong feedforward inhibition of MTCs (Shao et al., 2012, 2013). These ETC-driven indirect pathways have been proposed to be the sole or predominant circuits underlying IGC action on MTCs (Whitesell et al., 2013; Banerjee et al., 2015).

Here we combined in vitro and in vivo electrophysiology with optogenetics in transgenic mice to determine whether the IGC directly impacts MTCs. In contrast to previous studies (Whitesell et al., 2013; Banerjee et al., 2015), we find that the IGC directly and potently inhibits MTCs in parallel with the ETC-driven indirect pathways. We further demonstrate that this direct, monosynaptic connection is mediated by both GABAergic and electrical synapses. The IGC GABAergic inhibition is temporally amplified by MTC intrinsic properties and dominates over electrical synapse-mediated excitation to potently reduce MTC responses to sensory input for hundreds of milliseconds.

\section{Materials and Methods}

Animals. Wild-type male mice (C57BL/6J) and transgenic TH-Cre mice (B6.Cg-Tg(Th-cre)1Tmd/J, RRID: IMSR_JAX:008601) were obtained from Charles River and The Jackson Laboratory, respectively. A colony of transgenic animals was maintained by breeding heterozygous male $\mathrm{TH}-$ Cre mice with wild-type C57BL/6J female mice. Animals were maintained with a standard $12 \mathrm{~h}$ light/dark cycle and given food and water ad libitum. All experimental procedures were performed in accordance with protocols approved by the University of Maryland Institutional Animal Care and Use Committee.

Channelrhodopsin 2 (ChR2) expression. ChR2 was expressed in SACs as described previously (Liu et al., 2013). Briefly, the Cre-inducible adenoassociated virus serotype 9 (AAV2.9) carrying fusion genes for ChR2 and enhanced yellow (AAV2.9-hSyn-hChR2(H134R)-EYFP) or mCherry fluorescent protein (AAV-hSyn-hChR2(H134R)-mCherry) (Tsai et al., 2009) (University of Pennsylvania Vector Core) were injected into the glomerular layer (GL) of the medial side of each OB between postnatal weeks 4 and 6. Under deep anesthesia, the skull was exposed and a small hole ( $\sim 0.5 \mathrm{~mm}$ diameter) drilled over each OB at coordinates at $3.95 \mathrm{~mm}$ from bregma and $0.2 \mathrm{~mm}$ from midline. AAV2.9 was injected into three points within the GL of the medial side of each bulb (depth $2.0 \mathrm{~mm}, 1.5$ $\mathrm{mm}$, and $1.0 \mathrm{~mm}$ ) at a rate of $0.1 \mu \mathrm{l} / \mathrm{min}$ for $5 \mathrm{~min}$ with a total volume of $0.5 \mu \mathrm{l}$ per bulb. After 2-3 weeks for ChR2-EYFP or -mCherry fluorescent protein expression, acute horizontal OB slices were prepared for experiments as described previously (Liu and Shipley, 2008b).

Slice preparation. Acute OB slices from 8- to 12-week-old male or female mice were prepared as previously described (Liu and Shipley, 2008b). Briefly, horizontal slices $(350 \mu \mathrm{m})$ were cut with a VT1200 s vibratome in an ice-cold and oxygenated $\left(95 \% \mathrm{O}_{2}-5 \% \mathrm{CO}_{2}\right)$ sucrose-based ACSF containing the following: (in mM): 204.5 sucrose, $3 \mathrm{KCl}, 1.25 \mathrm{NaH}_{2} \mathrm{PO}_{4}, 2.6 \mathrm{MgSO}_{4}, 0.5 \mathrm{CaCl}_{2}$, $26 \mathrm{NaHCO}_{3}, 10$ glucose. After $30 \mathrm{~min}$ incubation in normal ACSF at $30^{\circ} \mathrm{C}$, slices were then transferred to ACSF at room temperature until they were used for experiments. Normal ACSF was continuously bubbled with $95 \%$ $\mathrm{O}_{2}-5 \% \mathrm{CO}_{2}$ and had the following composition (in mM): $124 \mathrm{NaCl}, 3 \mathrm{KCl}$, $1.25 \mathrm{NaH}_{2} \mathrm{PO}_{4}, 1.3 \mathrm{MgSO}_{4}, 1.3 \mathrm{CaCl}_{2}, 26 \mathrm{NaHCO}_{3}, 10$ glucose. During experiments, slices were perfused at $3 \mathrm{ml} / \mathrm{min}$ with ACSF equilibrated with $95 \% \mathrm{O}_{2}-5 \% \mathrm{CO}_{2}$ and warmed to $30^{\circ} \mathrm{C}$.

In vitro electrophysiology. Whole-cell patch-clamp or cell-attached recordings were made from MTCs or ETCs visualized using a BX50WI
(Olympus) fixed-stage upright microscope equipped with near-infrared differential interference contrast optics. MTCs were identified by their location, cell size, and presence of lateral/primary dendrites. ETCs were identified as previously described (Liu, Aungst et al., 2012). Briefly, they are identified for experiments based on the following three criteria: (1) spontaneous intrinsic burst firing that persists even when fast synaptic transmitter (AMPA, NMDA, and $\mathrm{GABA}_{\mathrm{A}}$ ) receptors are blocked; (2) "pear"-shaped cell body located in the deep half of the GL when viewed in infrared differential interference contrast optics; and (3) an apical dendrite with extensively ramified tuft confined to the glomerulus and absence of lateral dendrites in the external plexiform layer.

Current or voltage signals were recorded with a MultiClamp 700B amplifier (Molecular Devices) and low-pass filtered at $4 \mathrm{kHz}$ and sampled at $10 \mathrm{kHz}$ with a DIGIDATA 1322A 16-bit analog-to-digital converter (Molecular Devices) using Clampex 9.2 (Molecular Devices). Patch recording electrodes were pulled from standard-wall glass capillary tubes without filament (Sutter Instruments). Patch pipettes (4-7 M $\Omega$ ) for whole-cell recording contained the following (in $\mathrm{mM}$ ): 115 K-gluconate, 5.0 EGTA, 0.63 $\mathrm{CaCl}_{2}, 5.5 \mathrm{MgCl}_{2}, 10 \mathrm{HEPES}, 3 \mathrm{Na}_{2}$-ATP, $0.3 \mathrm{Na}_{3}$-GTP, and 14 Tris-phosphocreatine, pH 7.3 (285-295 mOsm). The liquid junction potential $(11-13 \mathrm{mV})$ was not corrected. Access resistance was typically $<30 \mathrm{M} \Omega$ and not compensated.

Immunohistochemistry. OB slices (350 $\mu \mathrm{m}$ thickness) were fixed in $4 \%$ PFA for $24 \mathrm{~h}$ after physiological recordings, then embedded in $10 \%$ gelatin in $1 \times$ PBS and recut at $40 \mu \mathrm{m}$ using a vibratome (Leica). Immunohistochemistry was performed at room temperature on free-floating sections. Sections were incubated for $30 \mathrm{~min}$ in $2 \%$ BSA in TBST $(0.1 \mathrm{~m}$ Tris, $\mathrm{pH} 7.4$, $0.9 \%$ saline, and $0.3 \%$ Triton $\mathrm{X}-100$ ) and then incubated overnight with a mouse anti-TH antibody (1:20,000; Immunostar, RRID:AB_572268). Sections were rinsed in TBST ( 3 washes of 10 min duration) and incubated in anti-mouse Cy3-conjugated secondary antibodies (1:1000; Jackson ImmunoResearch Laboratories) for $2 \mathrm{~h}$ at room temperature. EYFP was detected by the intrinsic fluorescence of the molecule. Sections were rinsed in TBST ( 3 washes of 10 min duration), mounted on gelatin-coated slides, and coverslipped with a 1,4-diazabicyclo-[2.2.2] octane-based anti-fade mounting media. Digital microscopy images were captured using a FluoView500 confocal microscope (Olympus) and assembled using CorelDraw X7 (Corel).

Surgery and in vivo electrophysiology. Surgery was performed in adult $(8-12$ weeks old) male $(n=4)$ and female $(n=4)$ TH-Cre mice with viral-ChR2 injection and expression as described above. Animals were anesthetized with intraperitoneal injection of ketamine/xylazine mixture at an initial dose of $100 \mathrm{mg} / \mathrm{kg}$ ketamine and $10 \mathrm{mg} / \mathrm{kg}$ xylazine. The anesthesia level was judged by the dose at which the foot withdrawal reflex ceases and that the amplitude/rate of respiration measured by chest transducer was stable during the experiment (typically $1.5-3 \mathrm{~Hz}$ respiration). Supplemental doses of ketamine/xylazine mixture were used to maintain stable anesthesia throughout the surgery and recordings. The anesthetized animals were held in a stereotaxic device and body temperature maintained at $35^{\circ} \mathrm{C}-37^{\circ} \mathrm{C}$ with an insulated Peltier warming platform controlled and monitored by a thermoregulation device. After the skin was shaved and cut, a craniotomy opening ( $\sim 3 \mathrm{~mm}$ diameter) was made over the dorsal surface of the left OB using a dental drill and fine forceps. The dura was incised on the lateral side of the OB for recording electrode penetration

Extracellular single-unit recordings from MTCs on the medial sides of the left $\mathrm{OB}$ were performed with FHC tungsten microelectrodes with impedances ranging from 1 to $4 \mathrm{~m} \Omega$ as described previously (Zhan, Yin et al., 2013). The electrode was positioned with a $\sim 30^{\circ}$ angle to the horizontal plane and inserted gradually from lateral dorsal surface to the mitral layer on medial side of the bulb to ensure that the medial GL with the apical dendrites of recorded mitral cell (MC) was unperturbed. The medial mitral layer was determined both by advancing the predicted distance from the lateral bulb surface and by assessment of characteristic field/unit activity of each layer traversed to the medial side (lateral GL, external plexiform layer, mitral cell layer, granule cell layer to medial mitral cell layer). Single units and local field potentials were recorded by a Plexon system. Signals from the recording microelectrode were amplified in series by an op-amp head-stage (Plexon, HST/8050-G20-GR; 20X 
amplification) and a differential preamplifier (Plexon, PBX2/16SP-R/ 16FP-G50; $50 \times$ amplification). Single-unit signals were extracted by hardware high-pass filter $(>150 \mathrm{~Hz})$ and digitized at $20 \mathrm{kHz}$, whereas local field potentials were extracted by low pass filter $(<150 \mathrm{~Hz})$ and digitized at $4 \mathrm{kHz}$.

Electrical and optical stimulation. Electrical stimulation was delivered by bipolar glass electrodes made from theta borosilicate tubes (Sutter Instruments). The isolated and constant current stimulation pulses (100 $\mu$ s) were triggered by a PG4000A digital stimulator (Cygnus Technology) or Master-8 stimulator (A.M.P.I.). Optical stimuli were delivered from a multimode optical fiber with opening diameter of $200 \mu \mathrm{m}$ in vivo $(0.48$ $\mathrm{NA}, \sim 15^{\circ}$ beam divergence) or $25 \mu \mathrm{m}$ in vitro $\left(0.1 \mathrm{NA}, \sim 7^{\circ}\right.$ beam divergence). Optical stimulation was (ThorLabs) produced by a $100 \mathrm{~mW}, 473$ $\mathrm{nm}$, diode-pumped, solid-state laser MBL-III-473 (Optoengine) and gated with a laser shutter LST200 (NMLaser Products). Optical power delivered at the fiber tip was calibrated with a PM20A power meter (ThorLabs). For in vitro and in vivo recordings, onset and duration of optical stimulation were measured during every experiment by splitting $1 \%$ of the laser beam out to a high speed (30 ns rise-time) silicon photosensor (model 818-BB, Newport) and recorded by the same MultiClamp 700B amplifier (in vitro) as the patch electrode or recorded by the same Plexon system as the single-unit recordings (in vivo).

Data analysis. In vitro data were first analyzed with Clampfit 9.2 (Molecular Devices). In vivo data were first sorted with the Offline Sorter (version 2.8.8, Plexon) before further analyses with NeuroExplorer (Nex Technologies). Numerical calculation and analysis were done with $\mathrm{Mi}-$ crosoft Excel. Statistical analysis was performed with Origin, 2015 (Origin Lab) and NCSS 8 (NCSS). Statistical significance of population responses were calculated by using Student's $t$ test or ANOVA with Bonferroni post hoc comparisons. Graphs and plotting were created with NeuroExplorer, Origin 2015, and SigmaPlot 9.0 (Systat software). Sex differences between male/female animals in experiments were evaluated and none observed.

Drugs and chemicals. APV $(50 \mu \mathrm{M}), \mathrm{NBQX}$ (disodium salt, $10 \mu \mathrm{M}$ ), gabazine (GBZ; SR95531, $10 \mu \mathrm{M}$ ), 8-bromo-2,3,4,5-tetrahydro-3-methyl-5phenyl-1H-3-benzazepin-7-ol (SKF83566) hydrobromide (10 $\mu \mathrm{M})$, 8-[4(4-fluorophenyl)-4-oxobutyl]-1-phenyl-1,3,8-triazaspiro[4,5]decan-4-one (spiperone) hydrochloride $(10 \mu \mathrm{M})$, and $(3 \beta, 20 \beta)$-3-(3-carboxy-1-oxopropoxy)-11-oxoolean-12-en-29-oic acid (carbenoxolone [CBX]) disodium $(300 \mu \mathrm{M})$ were purchased from Tocris Cookson. All other chemicals were purchased from Sigma-Aldrich. All drugs were bath applied by diluting in ACSF at the above-indicated doses unless otherwise stated.

\section{Results}

\section{Direct and indirect IGC inhibition of MTCs}

The IGC is formed by SACs, which project to multiple glomeruli where they could make synaptic connections with the apical dendrites of MTCs as well as local glomerular neurons, including excitatory ETCs and inhibitory PGCs and SACs. In vitro and in vivo activation of IGC with electrical or optogenetic stimulation produces inhibition of MTCs (Aungst et al., 2003; Whitesell et al., 2013; Banerjee et al., 2015). However, the precise circuitry and synaptic actions of IGC are still unclear. MTCs receive direct synaptic input from $\mathrm{ON}$ terminals as well as local excitatory (ETCs) and inhibitory (PGCs and SACs) interneurons (Hayar et al., 2004; De Saint Jan et al., 2009; Shao et al., 2009; Gire et al., 2012). The IGC monosynaptically targets ETCs and causes fast, $\mathrm{GABA}_{\mathrm{A}}$ receptor-mediated inhibition followed by slower, DA receptor-mediated, rebound excitation (Liu et al., 2013). ETCs monosynaptically excite MTCs (De Saint Jan et al., 2009; Gire et al., 2012) and the majority of PGCs (Shao et al., 2009). Thus, at least two indirect IGC pathways, $\mathrm{SAC} \rightarrow \mathrm{ETC} \rightarrow \mathrm{MTC}$ and $\mathrm{SAC} \rightarrow \mathrm{ETC} \rightarrow \mathrm{PGC} \rightarrow \mathrm{MTC}$, could mediate IGC's impact on MTCs, as suggested by previous studies (Whitesell et al., 2013; Banerjee et al., 2015). The SAC $\rightarrow$ ETC $\rightarrow$ MTC pathway would reduce excitation of MTCs and the $\mathrm{SAC} \rightarrow \mathrm{ETC} \rightarrow \mathrm{PGC} \rightarrow \mathrm{MTC}$ pathway could produce a reduction followed by an enhancement of inhibition. However, another possibility is that GABAergic SACs directly, monosynaptically inhibit MTCs.

To investigate these possibilities, MTCs were voltage-clamped at $-60 \mathrm{mV}$, and their responses to optical activation of ChR2 expressing SACs were recorded in OB slices of TH-Cre mice. Consistent with the previous studies (Liu et al., 2013), ChR2expressing neurons are restricted in the OB GL (Fig. $1 A$ ). Immunohistochemical staining (Fig. $1 B-D$ ) showed that $90.8 \pm 0.6 \%$ of ChR2-expressing neurons are TH protein-positive $(n=108$ cells from 3 mice, data previously reported) (Liu et al., 2013). The remaining $\sim 10 \%$ may represent immature SACs that express the $\mathrm{TH}$ gene and drive ChR2 but do not yet express detectable levels of TH protein (Baker et al., 2001; Saino-Saito et al., 2004). Previous studies show that $<10 \%$ of $\mathrm{TH}^{+}$glomerular neurons coexpress GAD65 (Kosaka and Kosaka, 2008; Kiyokage et al., 2010), a molecular marker of PGCs that have single dendrites restricting to individual glomeruli. Thus, to avoid possible PGC actions, optically stimulated glomeruli were separated from the glomeruli containing the apical dendrites of the recorded MTCs by 3-4 glomeruli (Fig. 1E, inset) (Liu et al., 2013) unless otherwise indicated.

Brief (2 ms) optical activation of SACs evoked long-lasting outward currents in MTCs (Fig. 1E). These currents had an initial peak with a rise-to-peak time of $31.5 \pm 2.3 \mathrm{~ms}(n=8)$, followed by a sustained plateau. The half-peak width of these outward currents ranged from 367 to $723 \mathrm{~ms}(412.8 \pm 25.1 \mathrm{~ms}, n=8)$. When the IGC indirect pathways via $\mathrm{ETC} \rightarrow \mathrm{MTC}$ and ETC $\rightarrow$ PGC synapses were blocked with fast glutamate receptor antagonists NBQX and APV, the duration of these outward current was shortened to a half-peak width of $57.2 \pm 8.6 \mathrm{~ms}(n=8$, $p<0.001$; Fig. $1 F)$ and total charge reduced from $40.6 \pm 6.7$ $\mathrm{nA} \times \mathrm{ms}$ to $4.8 \pm 1.4 \mathrm{nA} \times \mathrm{ms}(n=8, p<0.001$; Fig. $1 G)$. However, the initial time-to-peak latency was unaltered $(32.4 \pm$ $1.3 \mathrm{~ms}, n=8$, compared with before NBQX and APV) and peak amplitude reduced by only $12.7 \pm 3.4 \%(p<0.05, n=8)$. Moreover, with the IGC indirect pathways blocked, the onset latency of the outward current ranged from 2.1 to $2.8 \mathrm{~ms}$ ( $2.40 \pm$ $0.04 \mathrm{~ms}, n=8$ ) with synaptic jitter (SD of latency) of $174 \pm 11 \mu \mathrm{s}$ $(n=8$; Fig. $1 H)$. The short, consistent latencies of the NBQX/ APV-resistant, SAC-evoked outward currents conform to a direct, monosynaptic, inhibitory connection from SACs to MTCs. Collectively, these findings demonstrate that IGC inhibits MTCs by parallel circuits: direct, monosynaptic $\mathrm{SAC} \rightarrow \mathrm{MTC}$ inhibition that is prolonged by the indirect polysynaptic circuit involving $\mathrm{SAC} \rightarrow$ ETC synapses (Liu et al., 2013).

\section{Direct IGC input produces long-lasting inhibition of MTCs}

The finding that both direct and indirect pathways mediate IGC inhibition of MTCs sharply contrasts with previous studies reporting that indirect pathways are the sole or major mediators of IGC inhibition of MTCs (Whitesell et al., 2013; Banerjee et al., 2015). One explanation for this discrepancy is that impact of the direct SAC-MC connection on postsynaptic neuron firing is too subtle to be detected, especially by measuring intracellular $\mathrm{Ca}^{2+}$ signal changes (Banerjee et al., 2015). To test this idea, we examined MTC responses to brief ( $2 \mathrm{~ms}$ ) optical activation of the IGC with cell-attached recordings. Cell-attached recording provides high-fidelity spike data without altering intracellular chloride, which could impact the magnitude or even the polarity of $\mathrm{GABA}_{\mathrm{A}}$ receptor-mediated responses. Consistent with our whole-cell voltage-clamp results above, brief optical stimulation elicited a long-lasting inhibition of MTC firing (Fig. 2A). Next, we eliminated the contribution of the IGC indirect pathways by blocking 

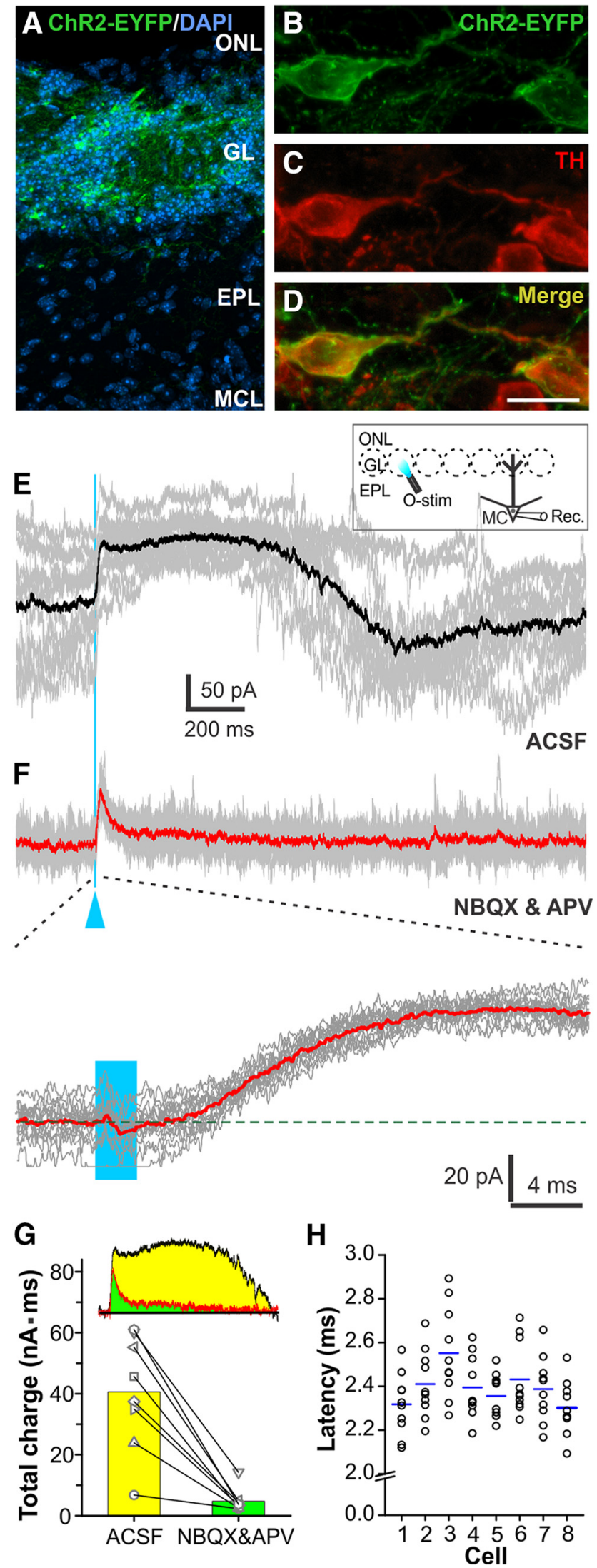

Figure 1. Direct and indirect transmission from SACs to MTCS. A-D, Confocal image of a horizontal $\mathrm{OB}$ section showing the expression of ChR2-EYFP selectively in the $\mathrm{GL}(\boldsymbol{A})$ and colocalization of TH protein and ChR2-EYFP $(\boldsymbol{B}-\boldsymbol{D})$ in SACS. $\boldsymbol{E}, \boldsymbol{F}$, Traces from an MTC voltageclamped at $-60 \mathrm{mV}$ showing outward currents in response to brief optical stimulation (blue
A
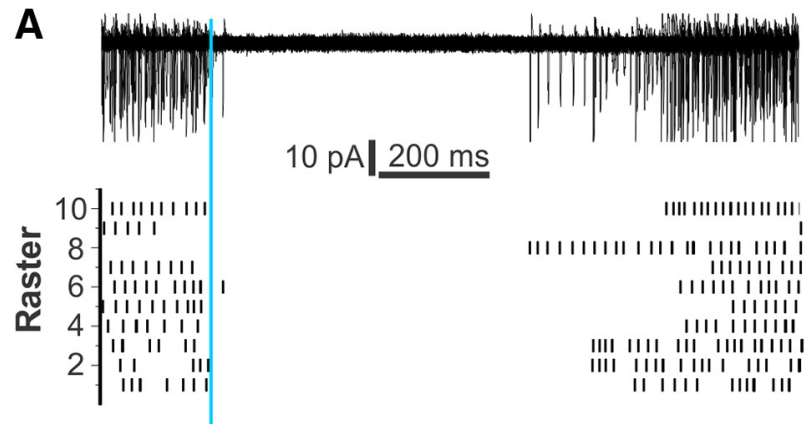

B
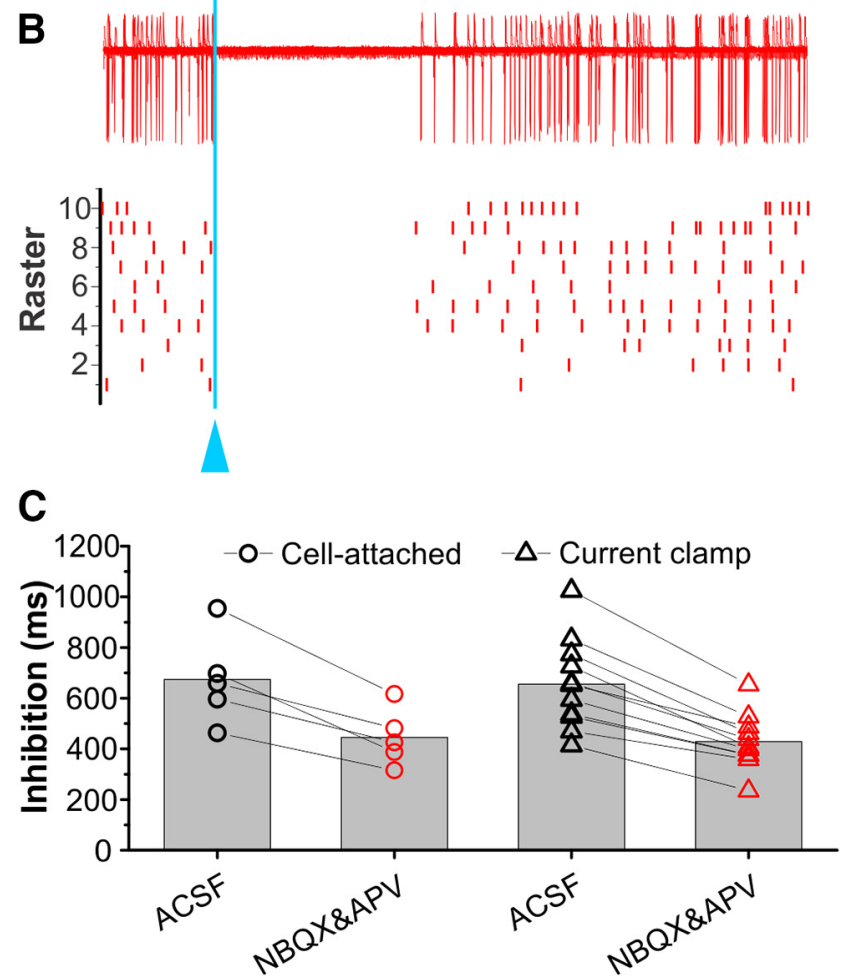

Figure 2. SAC activation produces long-lasting inhibition of MTCS. $A, B$, Cell-attached recordings showing that brief optical stimulation of $S A C S$ produces a long inhibition of MTC firing in the absence $(\boldsymbol{A})$ or presence of NBQX and APV $(\boldsymbol{B})$. Raster data showing spike firing activities of 10 recording traces in each conditions. C, Quantified data from 5 MTCs in cell-attached and 11 MTCs in current-clamp recording conditions showing the potent inhibition of MTCs by optical stimulation of SACs with or without fast glutamatergic synaptic blockers.

the glutamatergic ETC $\rightarrow$ MTC and ETC $\rightarrow$ PGC circuits with NBQX and APV. IGC inhibition duration was $671 \pm 81 \mathrm{~ms}$ $(n=5)$ in ACSF and $445 \pm 51 \mathrm{~ms}(n=5, p<0.05)$ in NBQX and APV (Fig. $2 B, C$ ). This shortened the duration of inhibition but not to the extent predicted from the inhibition duration change with NBQX/APV in our voltage-clamp findings (Fig. 1E,F). There are two possible explanations for this finding: (1) the typical internal solution used in voltage-clamp experiments alters the intracellular chloride concentration of MTCs such that the

line and arrowhead) of short axon cells in ACSF (E) or in the presence of NBQX and APV $(\boldsymbol{F})$. Black and red traces represent the average in each condition. $\boldsymbol{B}$, Inset, Experimental setup. Enlargement of traces in $\mathbf{C}$ at the bottom shows the short, consistent latencies of outward currents. $\boldsymbol{G}$, Quantified data from 8 cells showing the under curve area charge in conditions shown in $A$ (yellow) and $\boldsymbol{B}$ (green) as shown by the inset. $\boldsymbol{H}$, Scatter plot showing latencies of SAC-evoked outward currents in 8 MTCs in the presence of NBQX and APV. Blue horizontal bars represent the average value of each cell. 
contribution of the direct IGC pathway is underestimated; and/or (2) MTC intrinsic membrane properties amplify/prolong the effect of brief direct IGC-mediated outward current to cause long-lasting inhibition of spiking.

To test the first possibility, we recorded MTCs in current clamp using the same internal solution as in the voltage-clamp experiments. The duration IGC-evoked inhibition of MTC firing was $656 \pm 53 \mathrm{~ms}$ $(n=11)$ in ACSF and $429 \pm 32 \mathrm{~ms}(n=$ 11) in NBQX and APV (Fig. 2C), neither of which is statistically different from durations recorded in cell-attached mode $(671 \pm 81 \mathrm{~ms}$ in ACSF and $445 \pm 51 \mathrm{~ms}$ in NBQX and APV, $n=5$ ). Thus, the prolonged duration of IGC $\rightarrow$ MTC inhibition is not due to altered intracellular chloride concentration by the internal solution in patch-clamp electrodes.

Intrinsic properties of postsynaptic neurons that amplify the actions of synaptic input have been reported in multiple classes of neurons. For example, persistent inward currents and T-type calcium currents prolong or enhance excitatory synaptic inputevoked membrane depolarization or firing in neocortical pyramidal neurons (Stuart and Sakmann, 1995), spinal motoneurons (Hultborn et al., 2004; Heckman et al., 2008), thalamic reticular neurons (Crandall et al., 2010), olfactory bulb ETCs (Liu and Shipley, 2008a), and MCs (Johnston and Delaney, 2010). Amplification of inhibitory synaptic inputs by postsynaptic voltagedependent conductances has been reported in cortical pyramidal neurons (Williams and Stuart, 2003) and cerebellar Purkinje neurons (Solinas et al., 2006). Thus, the interplay between synaptic inputs and the intrinsic properties of the postsynaptic neuron are critical determinants in many neural circuits. If the long-lasting IGC inhibition of MTCs is due to intrinsic properties of MTCs, rather than a circuit effect, then injecting brief hyperpolarizing currents into MTCs should elicit similar long-lasting inhibition. To investigate this, we first averaged IGC-evoked IPSCs in 8 MTCs measured with the indirect IGC pathway blocked by NBQX and APV, yielding average peak amplitude $75.6 \mathrm{pA}$, decay time constant (tau) $41.5 \mathrm{~ms}$ $(\sim 100 \mathrm{~ms}$ total duration), and the total charge $5.8 \mathrm{nA} / \mathrm{ms}$. Injection of this "simulated," direct IGC IPSC produced robust inhibition in 8 of 8 MTCs recorded in ACSF (Fig. 3A, left traces and PSTH graph). The duration of inhibition ranged from 350 to $770 \mathrm{~ms}$ (mean $545.2 \pm 45.2 \mathrm{~ms}, n=8$; Fig. $3 C$ ), which was $354 \%$ longer than the duration of the simulated IPSC ( $p<0.001 ; n=8$; Fig. $3 A$ ). This long-lasting inhibition was unchanged after blocking circuit influences with NBQX, APV, and GBZ (average duration $513.9 \pm 41.8$ ms; $n=8, p>0.05$ compared with $545.2 \pm 45.2$ ms in ACSF; Fig. $3 A, C)$. Together, these findings suggest that MTC intrinsic properties prolong the impact of brief inhibitory inputs.

How might this work? In healthy MTCs, the membrane potential alternates between an upstate and downstate (Heyward et al., 2001). The upstate results from a balance between the inward persistent sodium current $\left(\mathrm{I}_{\mathrm{NaP}}\right)$ (Heyward et al., 2001; Hage and Salkoff, 2012) and outward current(s). The simulated IGC IPSC may hyperpolarize the MTC membrane potential below the activation threshold for $\mathrm{I}_{\mathrm{NaP}}$ and thus terminate MTC spontaneous/evoked spiking by pushing cells into the downstate. Because MTCs have relatively weak hyperpolarization-activated cation current $\left(\mathrm{I}_{\mathrm{h}}\right)$ (Angelo and Margrie, 2011; Angelo et al., 2012), strong and/or synchronous inhibitory synaptic input will generate prolonged inhibition of MTCs until the membrane slowly ramps back to the activation threshold of $\mathrm{I}_{\mathrm{NaP}}$ that brings membrane potential to the upstate. If this is true, then one predication is that long-lasting inhibition of MTCs can be triggered by even very brief membrane hyperpolarization. To test this prediction, we recorded MTC responses to hyperpolarizing current pulses of varying amplitude and duration (Fig. $3 \mathrm{~B}, \mathrm{C}$ ). Injection of $50 \mathrm{pA}$ pulses with duration of 50 or $100 \mathrm{~ms}$ produced consistent longlasting inhibition with durations of $178.8 \pm 24.0 \mathrm{~ms}(n=8)$ or $341.3 \pm 35.7 \mathrm{~ms}(n=8)$, which approximates to $\sim 3.6(50 \mathrm{~ms})$ or 3.4 $(100 \mathrm{~ms})$ times the corresponding hyperpolarizing pulse duration. Increasing the pulse amplitude to $100 \mathrm{pA}$ generated longer MTC lasting inhibition for both the $50 \mathrm{~ms}(445.0 \pm 50.5 \mathrm{~ms}, n=8, p<$ $0.001 \mathrm{vs} 178.8 \pm 24.0 \mathrm{~ms}$ with $50 \mathrm{pA})$ and $100 \mathrm{~ms}(476.3 \pm 28.0 \mathrm{~ms}$, $n=8, p<0.005$ vs $341.3 \pm 35.7 \mathrm{~ms}$ with $50 \mathrm{pA}$ ) pulses. Because 50 

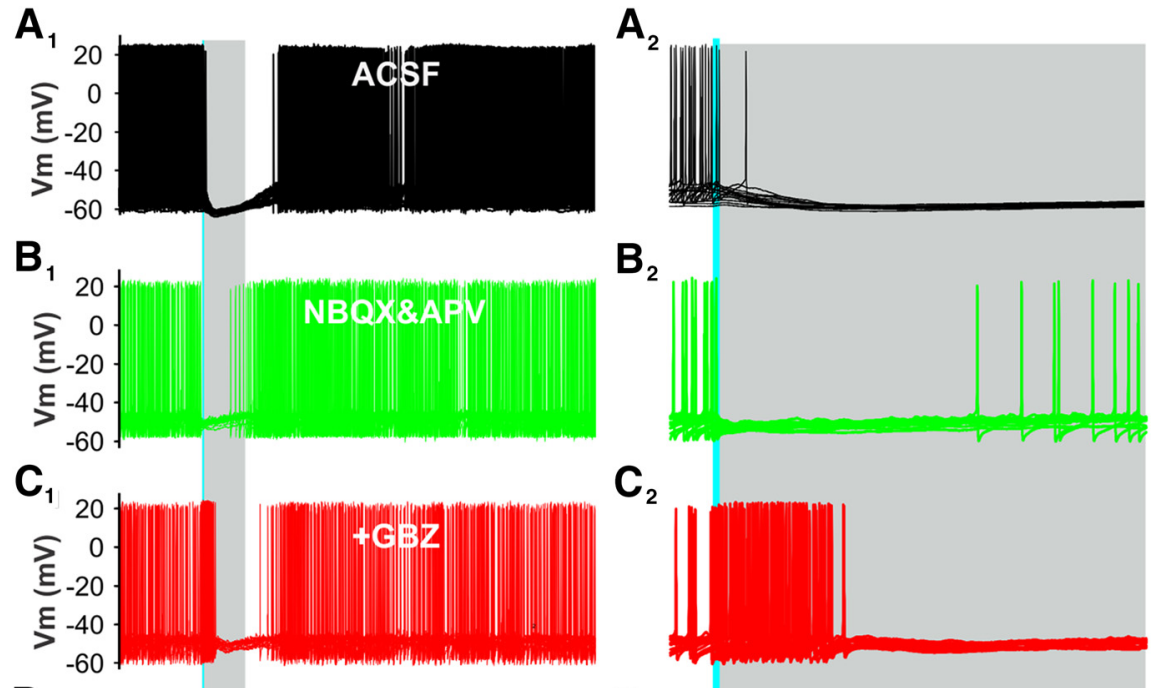

$\mathbf{B}_{2}$
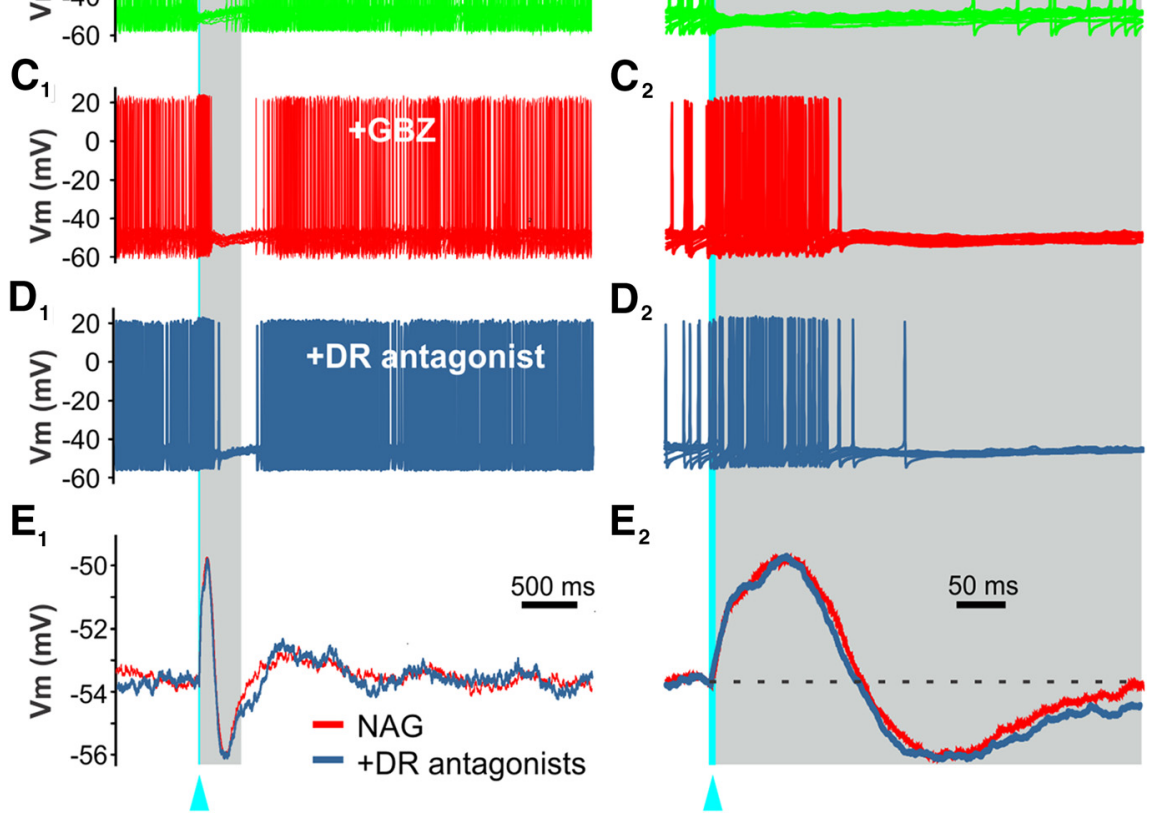

$\mathrm{D}_{2}$
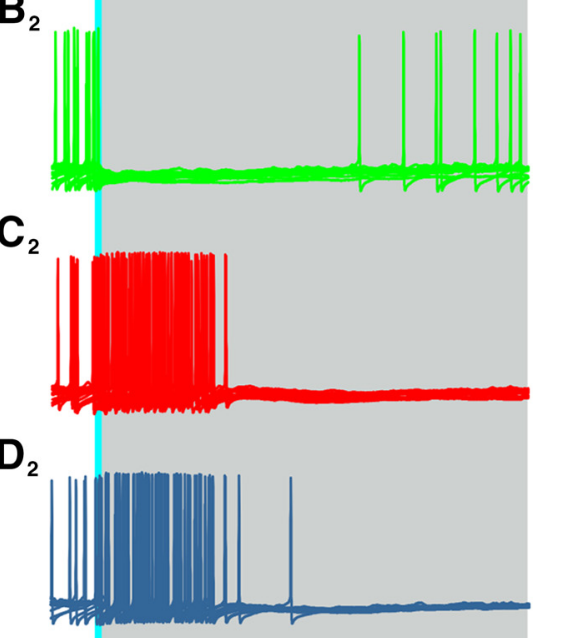

$\mathbf{E}_{2}$

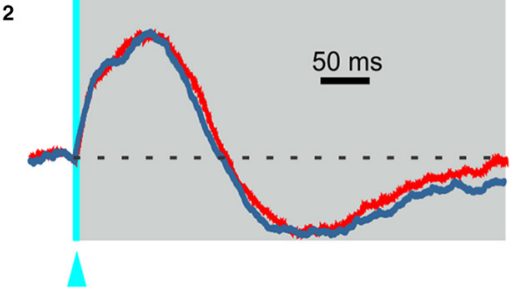

Figure 4. Block of ionotropic synaptic receptors switches SAC-MTC transmission from inhibition to excitation. A1-D1, Ten superimposed current-clamp traces showing MTC responses to brief optical stimulation (blue vertical line) of SACS in ACSF (A1), in the presence of NBQX and APV (B1), addition of GBZ (C1), or DA receptor antagonists SKF83566 and spiperone (D1). E1, Traces averaged from 10 individual responses in the same cell with hyperpolarizing current injection to prevent spiking reveals a biphasic response: depolarization followed by hyperpolarization in the presence of NBQX, APV, and GBZ (NAG, red) or addition of DA receptor antagonists (dark blue). $A 2-E 2$, Enlargement of traces on the left side to highlight the following: (1) blocking glutamatergic transmission with NBQX and APV (B2) shortens the SAC inhibition of MTCs compared with $\boldsymbol{A 2}$; (2) addition of GBZ revealed a brief excitation immediately following optical stimulation in forms of firing (C2) or subthreshold depolarization (E2, red trace) followed by firing inhibition or hyperpolarization; and (3) further addition of DA receptor antagonists showed no effect on the excitation-inhibition responses (D2 compared with $\mathbf{2}$ and dark blue trace compared with red trace in E2).
To investigate this, we again isolated the IGC $\rightarrow$ MTC direct circuit with NBQX and APV to eliminate indirect pathways via ETCs and examined MTC responses to optical stimulation of SACs with and without $\mathrm{GABA}_{\mathrm{A}}$ and DA receptor antagonists. Activation of SACs evoked direct, short-onset latency inhibition of MTC firing in all tested cells with either current-clamp recording $\left(n=5\right.$; Fig. $\left.4 A_{1}-B_{2}\right)$ or cell-attached $(n=4$, data not shown). As results from cell-attached and current-clamp recordings were identical, spike data from these cells were pooled for analysis. Addition of the $\mathrm{GABA}_{\mathrm{A}}$ receptor blocker, GBZ, transformed the MTC responses from long-lasting inhibition $(497.3 \pm 15.9 \mathrm{~ms}, n=9)$ to brief highfrequency spiking (frequency $71.2 \pm 5.9 \mathrm{~Hz}$, duration $143.6 \pm 13.3 \mathrm{~ms}$ ) followed by inhibition of spiking $(568.2 \pm 14.1 \mathrm{~ms})$ in 9 of 9 MTCs recorded in either cell-attached or current-clamp conditions (Fig. $4 C_{1}, C_{2}$ ). Conversion of the initial portion of IGCevoked inhibition into excitation by the $\mathrm{GABA}_{\mathrm{A}}$ receptor blocker GBZ indicates that the direct, monosynaptic inhibition of MTCs is mediated by GABA released from SACs and dominates over an excitatory component of synaptic action.

What accounts for this IGC-evoked fast glutamate/GABA receptor-independent excitation-inhibition response? It could be the result of a pronounced spikeinduced after-hyperpolarization (AHP) that would be present only when spikes are elicited in MTCs (Dumenieu et al., 2015; Liu et al., 2015). If this were the case, eliminating the IGC-evoked MTC spiking should abolish the following inhibition, as there would be no spike-evoked AHP. To test this, we repeated the above currentclamp experiments with injected current to hyperpolarize MTCs below spiking $\mathrm{pA} / 100 \mathrm{~ms}$ and $100 \mathrm{pA} / 50 \mathrm{~ms}$ have the same charge $(5.0 \mathrm{nA} / \mathrm{ms})$ but result in different MTC inhibition duration $(341.3 \pm 35.7 \mathrm{~ms}$ vs $445.0 \pm 50.5 \mathrm{~ms}, n=8, p<0.01$ ), we conclude that charge is not the primary driver of MTC inhibition response to the IGC. Rather, input current amplitude is more important than duration for intrinsic amplification of inhibition in MTCs. With larger amplitude pulses, the inhibition duration is $\sim 8.9$ and 4.8 times the 50 and $100 \mathrm{~ms}$ pulses, respectively. Together, these data show that MTC intrinsic properties preferentially prolong strong inhibition $(>50 \mathrm{pA})$, such as that evoked by IGC activation. Therefore, circuit-level inhibition is not only a function of presynaptic activity but can also be strongly shaped by the intrinsic properties of the postsynaptic neuron.

\section{Is direct $\mathrm{SAC} \rightarrow \mathrm{MTC}$ transmission mediated by coreleased GABA and DA?}

GABA and DA corelease by SACs produces an inhibitory-excitatory sequence in postsynaptic ETCs (Liu et al., 2013). Moreover, the $\mathrm{SAC} \rightarrow$ ETC synapse is reported to support electrical coupling (Banerjee et al., 2015). Is the direct SAC $\rightarrow$ MTCs synapse also mediated by coreleased GABA and DA and does it support electrical coupling? threshold. In this condition, brief activation of SACs still evoked a depolarization followed by hyperpolarization, although no spiking was elicited (Fig. $4 E_{1}, E_{2}$ ). The depolarization lasted for $561.9 \pm 11.5 \mathrm{~ms}$ with a peak amplitude of $3.4 \pm 1.1 \mathrm{mV}(n=5)$, and the subsequent hyperpolarization had a duration of $602.4 \pm$ $21.3 \mathrm{~ms}(n=5)$ with a peak amplitude of $2.1 \pm 0.7 \mathrm{mV}(n=5)$. These results argue that a spike-dependent AHP is not the major contributor to the inhibitory component of the IGC-evoked, fast glutamate/GABA receptor-independent response in MTCs.

Could DA play a role in this complex response? GABA and DA are coreleased at SAC $\rightarrow$ ETC synapses (Borisovska et al., 2013; Liu et al., 2013). DA acts on D1- or D2-like receptors to produce excitatory or inhibitory actions in many other neurons (Beckstead et al., 2004; Govindaiah and Cox, 2005; Liu et al., 2013). However, IGC-evoked MTC responses were unaltered by DA antagonists. First, the IGC-evoked excitation-inhibition of firing responses identically exhibited in both cell-attached and current-clamp recordings in the presence of fast glutamatergic and GABAergic synaptic blockers showed no further change following addition of DA D1- and D2-like receptor antagonists, 
SKF83566 and spiperone (Fig. $4 C_{1}, C_{2}$ compared with Fig. $\left.4 D_{1}, D_{2}\right)$. The IGCevoked brief spiking in MTCs in the presence of DR antagonists had a frequency of $69.1 \pm 5.8 \mathrm{~Hz}(n=9$, not significant compared with pre-DA antagonists) and duration of $137.9 \pm 14.5 \mathrm{~ms}(n=9$, not significant compared with pre-DA antagonists), whereas the following inhibition of spiking lasted for $573.6 \pm 16.8 \mathrm{~ms}(n=9$, not significant compared with pre-DA antagonists). Second, the depolarization-hyperpolarization response sequence in current clamp with hyperpolarizing current injection (Fig. $4 E_{1}, E_{2}$ ) was also unaltered by the further addition of the DA D1- and D2like receptor antagonists, SKF83566 and spiperone (Fig. $4 E_{1}, E_{2}$, dark blue trace compared with red trace). The subthreshold response in current clamp in the presence of DA antagonists showed a depolarization duration of $557.8 \pm 9.8 \mathrm{~ms}$ and peak amplitude of $3.3 \pm 1.2 \mathrm{mV}$ followed by hyperpolarization with duration of $601 \pm 10.5 \mathrm{~ms}$ and peak amplitude of $2.0 \pm 0.9 \mathrm{mV}$. None of these parameters differed from those measured in pre-DA antagonist conditions ( $n=5$, not significant). These results indicate that the direct IGC $\rightarrow$ MTC synapse can generate an excitatory-inhibitory response sequence that is independent of glutamate, GABA, and DA. What could mediate this response?

\section{IGC-MTC synapses support strong electrical coupling; IGC-ETC synapses do not}

Gap junction-mediated electrical coupling has been reported between ETCs and MTCs affiliated with same glomerulus (De Saint Jan et al., 2009), and a recent study reported electrical synapses between SACs and ETCs (Banerjee et al., 2015). However, it is also possible that SACs directly couple with MTCs via gap junction. In this scenario, optical stimulation evokes spiking followed by AHP in SACs and that these excitation-inhibition currents are transferred to MTCs via gap junctions. If this were true, response duration in MTCs should vary with duration of SAC activation. The second prediction is that blocking electrical coupling should eliminate both the excitatory and inhibitory components of the IGC-evoked, glutamate/GABA receptor-independent excitation-inhibition response in MTCs. To test these predictions, we clamped MTCs at -60 $\mathrm{mV}$ and recorded their response to optical activation of IGC in the presence of the fast synaptic blockers NBQX, APV, and $\mathrm{GBZ}$, as before. Consistent with our current-clamp findings (Fig. $4 C_{1}-D_{2}$ ), MTCs responded to brief or long (1 s) IGC stimulation with brief or long inward currents, respectively
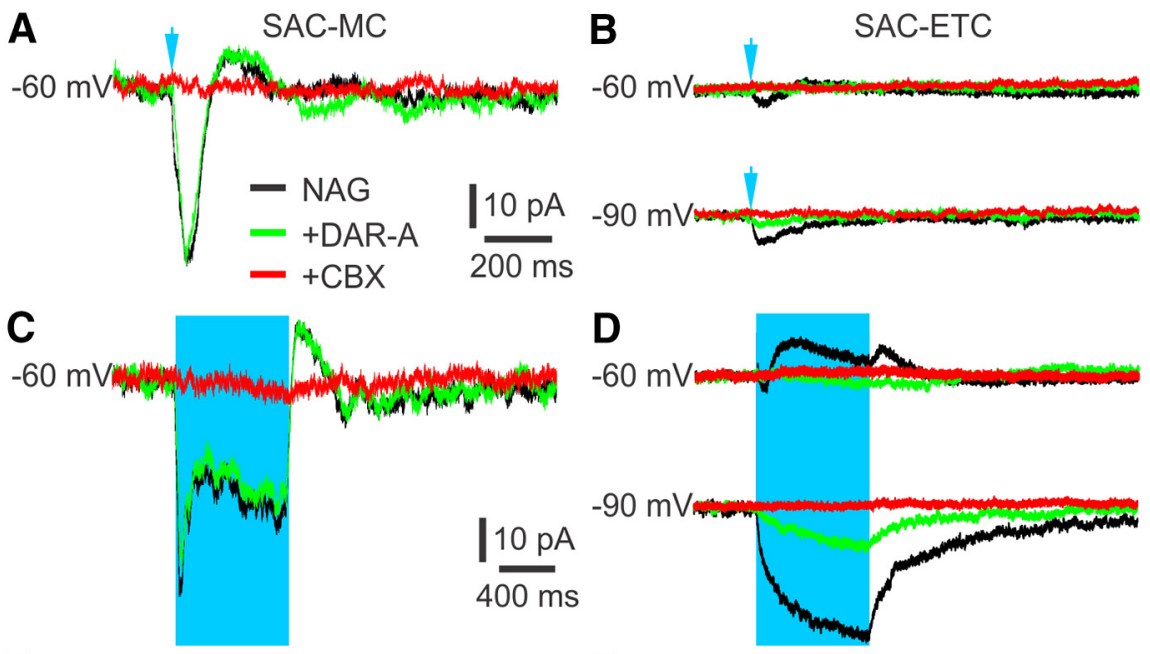

E
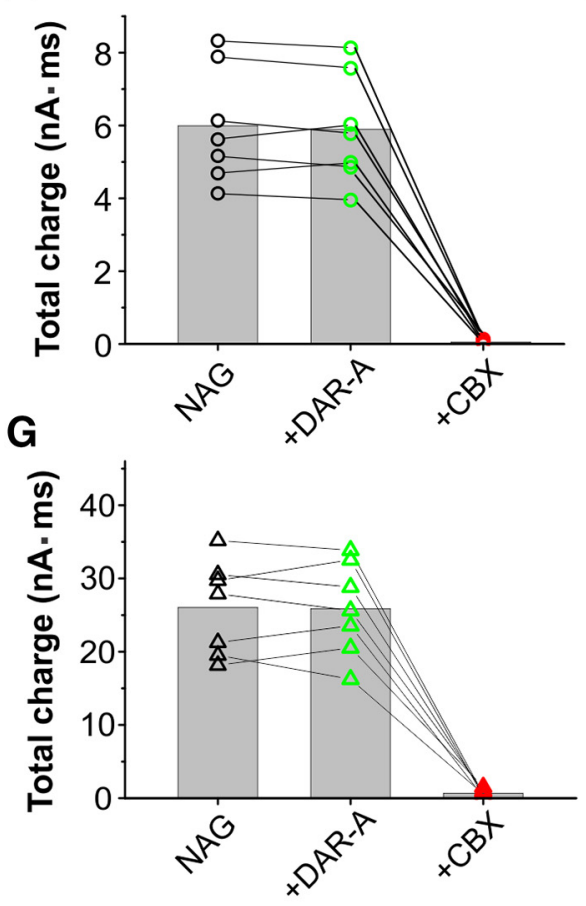

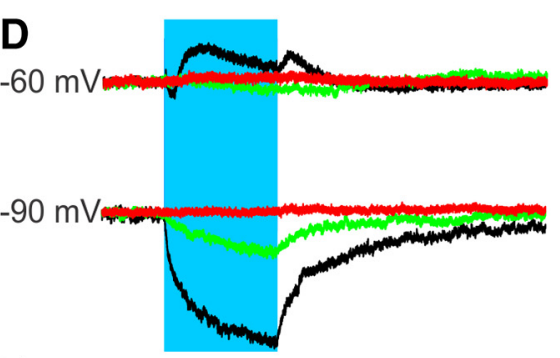

$\mathbf{F}$

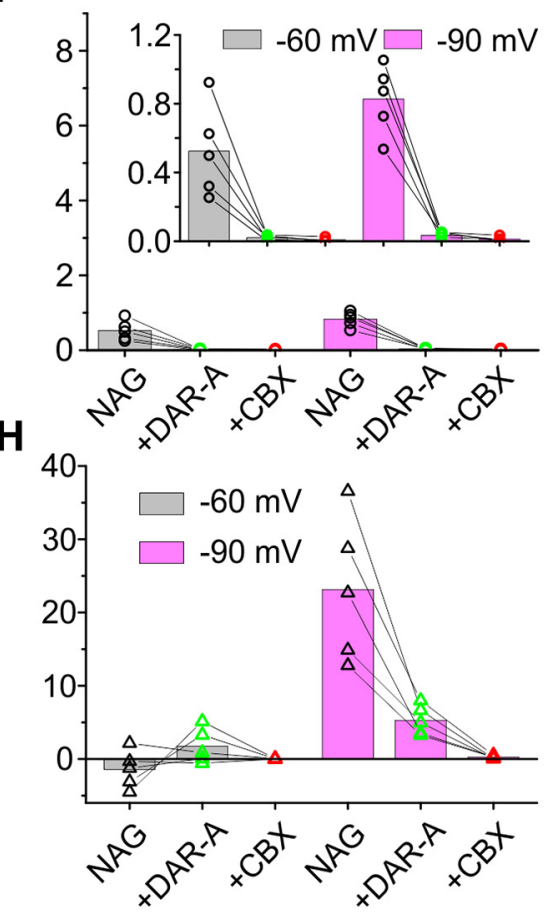

Figure 5. SAC-MTC electrical transmission is $\sim 10$-fold stronger than that of SAC-ETC. $A-D$, Typical averaged traces recorded from an MTC $(\boldsymbol{A}, \boldsymbol{C})$ voltage-clamped at $-60 \mathrm{mV}$ and an ETC $(\boldsymbol{B}, \boldsymbol{D})$ voltage-clamped at $-60 \mathrm{mV}$ (top) or $-90 \mathrm{mV}$ (bottom) in response to brief $(\boldsymbol{A}$, $\boldsymbol{B}$ ) or long (1 $s ; \boldsymbol{B}, \boldsymbol{D})$ optical stimulation of SACs in the presence of NBQX, APV, and GBZ (NAG, black), addition of DA receptor antagonists SKF83566 and spiperone (green), or further addition of $(B X$ (red). $E, F$, Quantified data showing that brief optical stimulation of SACs evokes much larger inward currents in MTCs $(n=7 ; \boldsymbol{E})$ than ETCs $(n=5 ; \boldsymbol{F})$ when they are held at $-60 \mathrm{mV}$ in the presence of NBQX, APV, and GBZ (NAG, black symbols). Response of ETCs held at $-90 \mathrm{mV}$ (magenta and black symbols) is stronger than that held at $-60 \mathrm{mV}$ (black symbols). $\boldsymbol{F}$, Inset, Same graph with an expanded abscissa scale. This response in MTCs is insensitive to DA receptor antagonists (E, green symbols) but abolished by gap junction blocker $C B X(\boldsymbol{E}$, red symbols) where the response in $\mathrm{ETCs}$ is abolished by DA receptor antagonists $(\boldsymbol{F}$, green symbols). $\boldsymbol{G}, \boldsymbol{H}$, Quantified data showing that 1 soptical stimulation of $S A C$ s evokes a larger inward currents in $\operatorname{MTC}(n=7 ; \boldsymbol{G}$, black symbol) but a smaller response mixed with inward or outward currents in $\operatorname{ETS}(n=5 ; \boldsymbol{H}$, black symbols) when they are held at $-60 \mathrm{mV}$ in the presence of NBQX, APV, and GBZ (NAG). When ETCs are held at $-90 \mathrm{mV}$, this stimulation evokes larger inward currents ( $\boldsymbol{H}$, black symbols). Responses of ETCs, but not MTCs, are sensitive to DA receptor antagonists (green symbols). Addition of (BX abolishes residual currents in both MTCs ( $\boldsymbol{G}$, red symbols) and ETCs ( $\boldsymbol{H}$, red symbols).

(Fig. 5A, C), followed by a small outward current. These currents were not altered by DA D1- and D2-like receptor antagonists (Fig. $5 A, C, E, G$ ), confirming that they are not mediated by DA. However, addition of the gap junction blocker CBX entirely abolished both responses (Fig. $5 A, C, E, G$ ). This shows that there is strong gap junction-mediated electrical coupling between SACs and MTCs. 
Could this electrical coupling be mediated by serial electrical synapses in a $\mathrm{SAC} \rightarrow \mathrm{ETC} \rightarrow$ MTC circuit, as suggested by a recent study (Banerjee et al., 2015)? Electrical synapses (unlike chemical synapses) lack gain as they allow passive current flow. However, due to cabling and capacitance properties of sequential cells, the response in the postsynaptic neuron is in general smaller in amplitude than the presynaptic neurons. Thus, if current flows via serial gap junctions from $\mathrm{SAC} \rightarrow \mathrm{ETC} \rightarrow$ MTC, then the SAC-ETC coupling should be at least equal to or slightly stronger than the IGC $\rightarrow$ MTC coupling. To test this, we voltage-clamped ETCs at $-60 \mathrm{mV}$, their average resting membrane potential (Liu and Shipley, 2008b), and recorded responses to optical activation of the IGC. Consistent with our previous study (Liu et al., 2013), brief activation of SACs evoked a small inward current in the presence of fast glutamatergic and GABAergic receptor blockers (Fig. $5 B$, top). This current had an average total charge of $0.52 \pm 0.12$ $\mathrm{nA} \times \mathrm{ms}(n=5$; Fig. $5 F)$. However, $94.7 \pm 3.5 \%(n=5)$ of this current was blocked by SKF83566 and spiperone $(0.021 \pm 0.007$ $\mathrm{nA} \times \mathrm{ms}, n=5, p<0.001$ ) (Fig. $5 B, F)$, indicating that it is mediated almost entirely by DA receptors. Addition of the gap junction blocker, CBX, abolished the residual current (5.3 \pm $0.8 \%$ ), indicating negligibly weak electrical coupling between SACs and ETCs at physiological membrane potentials $(-60 \mathrm{mV})$. Long (1 s) optical stimulation of the IGC evoked only a small, brief inward current in 4 of 5 ETCs (half peak width 17.2 \pm 4.1 ms: peak amplitude $3.4 \pm 1.1 \mathrm{pA}$, charge $0.34 \pm 0.11 \mathrm{nA} \times \mathrm{ms}$, $n=4$ ) followed by a larger, longer duration outward current (maximal amplitude $9.5 \pm 2.8 \mathrm{pA}$; half-width $237.3 \pm 15.4 \mathrm{~ms}$, charge $1.41 \pm 1.15 \mathrm{nA} \times \mathrm{ms}$; Fig. $5 \mathrm{D}, H)$. DA antagonists blocked $92.1 \pm 5.9 \%$ of this response (Fig. $5 H$ ) leaving only a small, long-lasting inward residual current $(1.75 \pm 1.07 \mathrm{nA} \times \mathrm{ms}$; Fig. $5 D, H)$ that was abolished by $\mathrm{CBX}(0.02 \pm 0.01 \mathrm{nA} \times \mathrm{ms}, n=5)$ (Fig. $5 D, H$ ). Thus, our findings indicate that $>90 \%$ of the IGCevoked inward current in ETCs is due to activation of DA receptors and that electrical coupling is negligible. These findings contrast starkly with the Banerjee et al. (2015) conclusion of IGCETC electrical synapses based on experiments testing neither DA receptor antagonists nor gap junction blockers.

We hypothesize that the IGC $\rightarrow$ ETC inward current, attributed to gap junctions by Banerjee et al. (2015) is actually due to DA enhancement of the hyperpolarization-activated cation current $I_{h}$ (Liu et al., 2013). If correct, then activation of the IGC should evoke even larger inward currents in ETCs held at the hyperpolarized voltages used by Banerjee et al. (2015), and these larger currents should also be blocked by DA receptor antagonists. To test this, we repeated these experiments in the same ETCs voltage-clamped at $-90 \mathrm{mV}$. Because $\mathrm{I}_{\mathrm{h}}$ current varies with both the amplitude and duration of hyperpolarization, we tested brief ( $2 \mathrm{~ms}$ ) and long (1 s) optical stimulation pulses. As predicted, both brief and long optical stimuli elicited larger inward currents at $-90 \mathrm{mV}$ (Fig. $5 B, D$ ) than at $-60 \mathrm{mV}$ (Fig. $5 F, H$ ). For brief IGC activation, ETCs responded with inward currents with an average total charge of $0.83 \pm 0.09 \mathrm{nA} \times \mathrm{ms}(n=5$; Fig. $5 F ; p<0.05$ compared with $0.52 \pm 0.12 \mathrm{nA} \times \mathrm{ms}$ at $-60 \mathrm{mV}$ with $2 \mathrm{~ms}$ stimulation) and for long pulses large inward current of $23.1 \pm 4.4 \mathrm{nA} \times \mathrm{ms}$ was elicited $(n=5$; Fig. $5 H$; $p<0.001$ compared with $0.34 \pm 0.11 \mathrm{nA} \times \mathrm{ms}$ inward charge at $-60 \mathrm{mV}$ with long stimulation). Moreover, as expected from our previous finding of DA enhancement of $\mathrm{I}_{\mathrm{h}}$ current in ETCs (Liu et al., 2013), DA receptor antagonists nearly completely abolished these IGC-evoked inward currents in ETCs held at $-90 \mathrm{mV}$. The current evoked by brief SAC activation was reduced by $96.4 \%$ to $0.03 \pm 0.01 \mathrm{nA} \times \mathrm{ms} ; n=5, p<0.05$; Figure $5 F$ ), whereas the current evoked by long SAC activation was reduced by $77.1 \%$ to $5.28 \pm 0.90 \mathrm{nA} \times \mathrm{ms} ; n=5, p<0.001$; Figure $5 \mathrm{H}$ ). Addition of the gap junction blocker CBX abolished these residual currents for both brief and long IGC activations (Fig. $5 F, H$ ). Therefore, even at extremely hyperpolarized levels, most of the SAC $\rightarrow$ ETC inward current is due to DA augmentation of $\mathrm{I}_{\mathrm{h}}$ and not electrical coupling.

Together, these findings demonstrate that gap junction coupling is strong between SACs and MTCs but negligible between SACs and ETCs at resting membrane potentials.

\section{IGC regulates $\mathrm{MTC}$ responses to $\mathrm{ON}$ input}

MTCs are the principal OB output neurons; they receive sensory input and transfer signals directly to the olfactory cortex and other downstream networks. Thus, modulation of MTC excitability impacts the OB input-output transformation function. We previously showed that electrical activation of neighboring glomeruli inhibited ON-evoked response in MTCs (Aungst et al., 2003), but this effect is most effective when delivered $\sim 100 \mathrm{~ms}$ subsequent to ON-evoked MTC responses (Shirley, Coddington et al., 2010). Electrical stimulation nonselectively activates all distant glomerular circuits: does selective SACs activation have the same temporal dynamic? To investigate this, we combined current-clamp recordings of MTCs with electrical stimulation of the $\mathrm{ON}$ and optogenetic activation of SACs at different time intervals in $\mathrm{OB}$ slices.

MTCs responded to ON electrical stimulation (E-stim) alone with long-duration ( $\sim 600 \mathrm{~ms}$ ) spike firing (Fig. $6 \mathrm{~A})$, consistent with previous studies showing $\mathrm{ON}$-evoked long-lasting depolarization and spiking in MTCs (Carlson et al., 2000; De Saint Jan et al., 2009; Shao et al., 2012). We expressed ON-evoked spiking within a $300 \mathrm{~ms}$ time window following $\mathrm{E}$ stimulation as a percentage of its baseline spontaneous firing averaged $>700 \mathrm{~ms}$ immediately before ON stimulation (Fig. 6G). MTC spiking evoked by $\mathrm{ON}$ stimulation alone was $762.7 \pm 154.1 \%(n=12)$ of baseline level (E-stim only in Fig. 6A, $G$ ). We then examined MTC responses to brief optical stimulation (O-stim, $2 \mathrm{~ms}$ ) of the IGC alone. As with the preceding findings (Figs. 1;2;4), activation of the IGC consistently produced a long-lasting inhibition in 12 of 12 MTCs (Fig. 6B). MTC spiking within a $300 \mathrm{~ms}$ time window following $\mathrm{O}$-stim was $5.9 \pm 1.1 \%$ of the spontaneous baseline level $(n=12)$. To assess the impact of SAC activation on ONevoked MTC spiking, ON stimulation was followed by optical stimulation of the IGC at time intervals ranging from 0 to $300 \mathrm{~ms}$. At all ON-IGC stimulation intervals, ON-evoked MTC spiking was immediately terminated by IGC stimulation (Fig. $6 C-F$ ). To better assess the impact of IGC activation on the ON-evoked MC output, spiking was also normalized to MC spiking within a 300 ms time window immediately following ON stimulation alone (Fig. $6 \mathrm{G}$, right side scale). At stimulation intervals of 0 or $10 \mathrm{~ms}$, the average MTC firing following ON stimulation was reduced to $11.1 \pm 6.2 \%$ or $63.1 \pm 16.2 \%$ of baseline firing and $1.5 \pm 0.7 \%$ or $9.3 \pm 2.2 \%$ of the ON-evoked firing, respectively (Fig. $6 B, C, G$ ), indicating that IGC activation strongly inhibits MTC spiking to levels lower than baseline spiking at these short ON-IGC stimulation intervals. When the ON-IGC interval increased from 30 to $300 \mathrm{~ms}$, MTC spiking was truncated upon IGC stimulation. To represent the impact of IGC on ON-evoked MTC spike output in a different analysis window, we quantified the MTC spiking within a $300 \mathrm{~ms}$ time window immediately following optical IGC activation. Regardless of when IGC activation occurred, MTC spiking was suppressed below spontaneous baseline level at all tested intervals (Fig. 6G), demonstrating potent truncation of 
MTC spike output by the IGC. Thus, selective IGC activation following ON stimulation immediately terminates MTC sensory responses in other glomeruli.

IGC activation reduces MTC sensitivity to subsequent sensory input

Brief, selective activation of the IGC causes, potent, long-lasting inhibition of MTC firing via direct and indirect pathways. Thus prior IGC activation might generate a long-lasting temporal window in which MTCs in other glomeruli are less sensitive to subsequent sensory input. To test this hypothesis, we recorded MTC response to $\mathrm{ON}$ stimulation when preceded by optogenetic activation of the IGC at time intervals from 0 to $600 \mathrm{~ms}$. MTC spiking evoked by ON stimulation (Estim) alone was increased by $669.5 \pm$ $124 \%$ over baseline levels (Fig. $7 A, F$ ) as in the previous experiment. However, ONevoked MTC spiking was strongly inhibited to below the spontaneous baseline levels when preceded by optical stimulation (O-stim) of the IGC within short time windows. At $\mathrm{O}$-stim $\rightarrow$ E-stim intervals of 0 or $50 \mathrm{~ms} \mathrm{ON-evoked} \mathrm{spiking} \mathrm{was}$ reduced to $9.6 \pm 5.6 \%(n=12)$ or $60.4 \pm$ $22 \%(n=12)$ of baseline spiking and $1.5 \pm 0.7 \%$ or $9.7 \pm 3.9 \%$ of ON-evoked spiking, respectively (Fig. $7 A, B, C, F$ ). When IGC activation preceded ON stimulation by 100-600 ms, ON-evoked MTC spiking incrementally changed from $257.6 \pm 85.8 \%$ to $422.4 \pm 54.2 \%$ of spontaneous baseline levels or $33.1 \pm 7.6 \%$ to $73.9 \pm 12.2 \%$ of ON-evoked spiking $(n=$ 12; Fig. $7 D, E, F)$, indicating significant IGC inhibition of MC response to subsequent $\mathrm{ON}$ input. These results demonstrate that, when activity in IGC precedes sensory signals, MTC responses are strongly suppressed. Thus, sensory input to a glomerulus may activate its IGC to suppress MTCs in other glomeruli receiving subsequent sensory signals for hundreds of milliseconds and thus reduce their relative impact on downstream olfactory networks.

\section{The IGC inhibits MTCs in vivo}

A recent in vivo study showed that longduration (10-500 ms) optogenetic activation of the IGC inhibited spontaneous and odor-evoked MTC firing (Banerjee et al., 2015). The present in vitro findings predict that brief selective activation of IGC should produce long-lasting inhibition of MTCs in vivo. To test this hypothesis, we used extracellular single-unit recordings in anesthetized intact mice to determine how MTCs respond to a brief

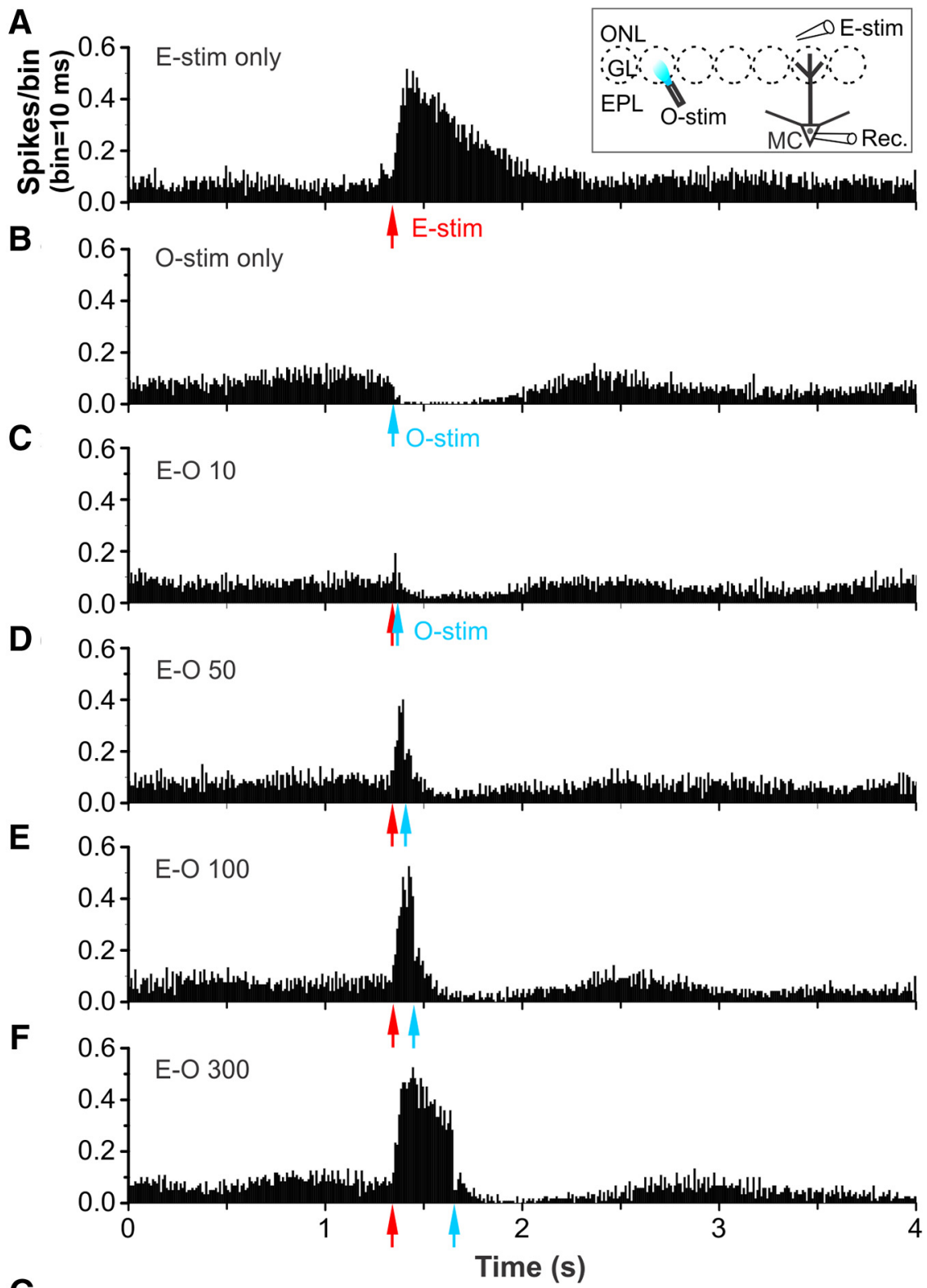

G

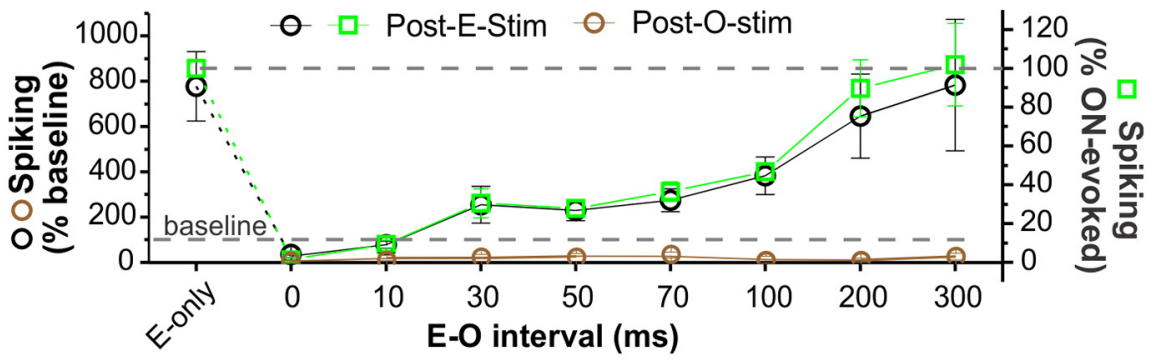

Figure 6. ON-evoked MTC responses are truncated by IGC input. A-F, Averaged PSTHs of current-clamp data from 12 MTCs showing MTC response to electrical stimulation (E-stim, red arrow) of ON $(\boldsymbol{A})$, brief optical stimulation ( 0 -stim, blue arrow) of the IGC (B), and E-stim followed by 0 -stim at different time intervals ranging from 10 to $300 \mathrm{~ms}(\boldsymbol{C}-\boldsymbol{F})$. $\boldsymbol{A}$, Inset, Schematic of experimental design. ONL, Olfactory nerve layer; EPL, external plexiform layer; Rec: recording electrode. $\mathbf{G}$, Quantified data showing the average $0 \mathrm{~N}$-evoked spiking activity within the $300 \mathrm{~ms}$ time window following E-stim (black square) or within the $300 \mathrm{~ms}$ time window following 0 -stim (green square) in 12 MTCs showing the impacted of subsequent activation of the IGC by 0 -stim at different time intervals $(0-300 \mathrm{~ms})$. Spiking is normalized to the baseline spontaneous level within a $700 \mathrm{~ms}$ time window before $\mathrm{E}$-stim or to the $0 \mathrm{~N}$-evoked spiking within a $300 \mathrm{~ms}$ time window following E-stim. 

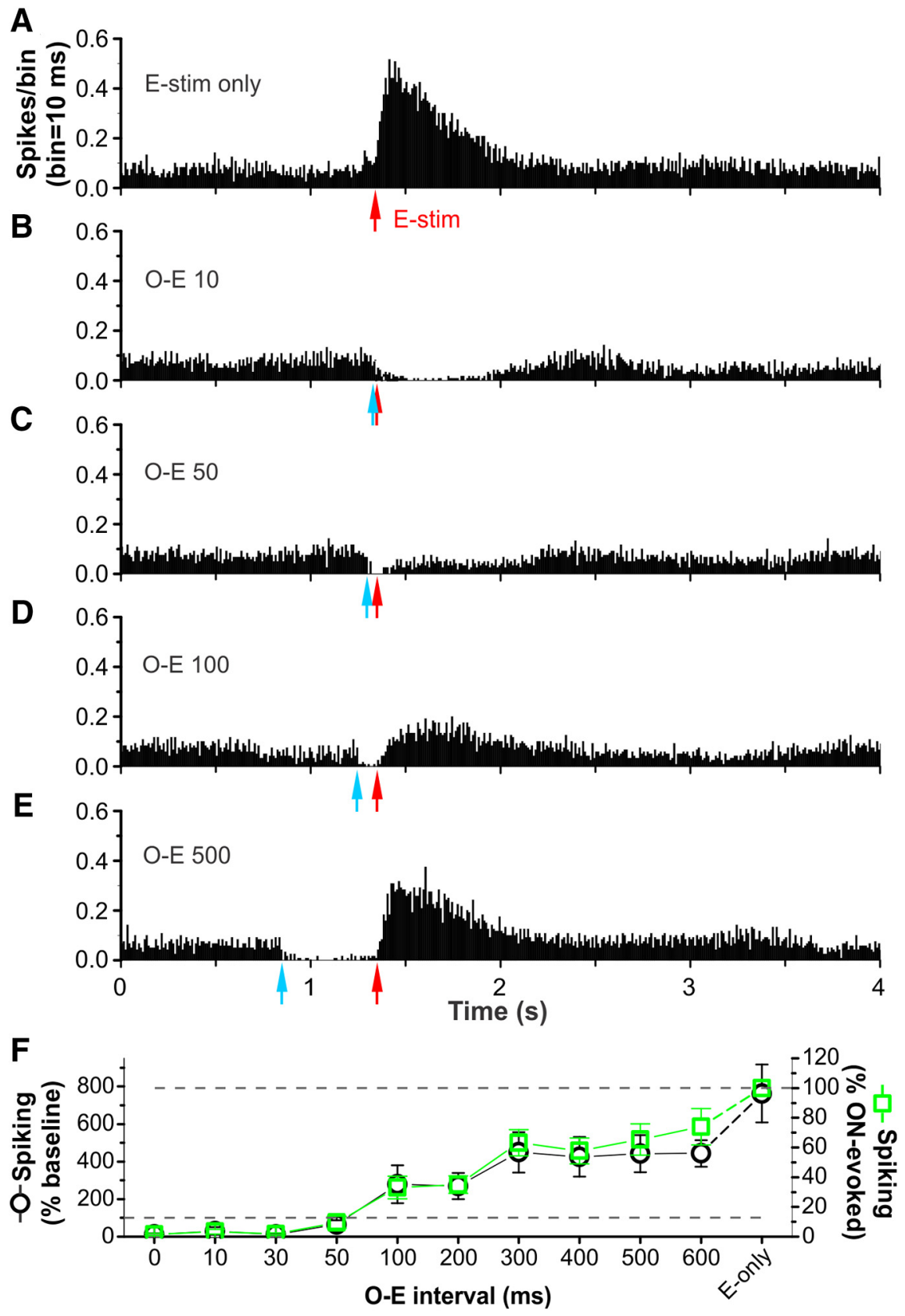

Figure 7. SAC activation potently inhibits MTC responses to subsequent ON input. $\boldsymbol{A}-\boldsymbol{E}$, Averaged PSTHs of currentclamp data from 12 MTCs showing MTC responses to electrical stimulation (E-stim, red arrows) of $\boldsymbol{A}$ or brief optical stimulation of SACS (0-stim, blue arrow) followed by E-stim at different time intervals $(\boldsymbol{B}-\boldsymbol{E})$. $\boldsymbol{A}$, Same as Figure $6 \boldsymbol{A}$. $\boldsymbol{F}$, Quantified data showing the average MTC $(n=12)$ spiking within a $300 \mathrm{~ms}$ analysis time window following E-stim and the impact of prior optical activation of the IGC at different time intervals ranging from 0 to $600 \mathrm{~ms}$. MTC spiking is normalized to the spontaneous baseline level within a 700 ms time window before 0 -stim (left axis) or to the $0 \mathrm{~N}$-evoked spiking within a 300 ms time window following $0 \mathrm{~N}$ stimulation (right axis).

(2 ms) optical activation of SACs expressing ChR2 (Fig. 8A). Optical stimulation was delivered via a $200 \mu \mathrm{m}$ optical fiber positioned vertically above the OB dorsal surface of the medial OB. Previous measures showed that a 2 ms light pulse elicits $\sim 4$ spikes from ChR2-expressing SACs (Liu et al., 2013). Although these single brief stimulation pulses elicit transient SAC spiking, they caused potent, long-lasting inhibition of MTC firing when delivered to the $\mathrm{OB}$ surface in the vicinity the recorded unit (Fig. $8 B, C)$. MTC inhibition lasted for $231.8 \pm 10.8 \mathrm{~ms}(n=24$ units from 8 mice; Fig. $8 C$ ), dramatically longer than the 2 ms optical stimulation. IGC activation of ETCs causes inhibition followed by robust rebound spiking (Liu et al., 2013). However, in MTCs, there was no significant rebound excitation following IGC inhibition $(102.9 \pm 8.1 \%$ of prestimulation baseline, $n=17, p>0.05)$. These findings demonstrate that brief ( 2 ms) IGC activation produces strong, long-lasting inhibition of MTC firing in vivo.

Mammals sample environmental odors by respiration or active sniffing; thus, the IGC would normally be repetitively activated by sensory input. How does such temporally dynamic IGC activity at sniffing frequencies influence MTC output? To address this question, we investigated repetitive IGC activity impact on MTC output. To approximate sniff-like activation of the IGC, we used trains of five brief ( $2 \mathrm{~ms}$ ) light pulses at three different frequencies: $2 \mathrm{~Hz}$ (normal mouse respiration rate), $5 \mathrm{~Hz}$ and 8 $\mathrm{Hz}$ (spanning mouse active sniffing frequencies) (Adrian, 1950; Verhagen et al., 2007). Each light pulse of the $2 \mathrm{~Hz}$ train stimulation produced a long-lasting inhibition of MTC firing equivalent to a single stimulation $(215.4 \pm 11.2 \mathrm{~ms}$ for the first pulse and $187.5 \pm 15.5 \mathrm{~ms}$ for the fifth pulse; Fig. $8 D ; n=14$ units from 5 mice). Thus, at this temporal interval, there is sufficient time for near full recovery to baseline spiking before the next pulse. However, as input frequency was increased to 5 or $8 \mathrm{~Hz}$, MTCs were continuously inhibited throughout the stimulation epoch (Fig. 8D). Even with high-frequency trains, inhibition was followed by only minor rebound excitation $(119.2 \pm 11.1 \%$ and $126.6 \pm 15.9 \%$ of prestimulation baseline for $5 \mathrm{~Hz}$ and $8 \mathrm{~Hz}$, $n=14, p>0.05)$. These observations demonstrate potent IGC inhibition of the OB output neurons at all tested input frequencies. Inhibition becomes continuous when input frequencies approximates the range of active sniffing.

Approximately two-thirds of SACs receive their most effective excitatory drive from ETCs (Kiyokage et al., 2010), which respond to ON input with a burst of 3-5 spikes with interspike frequency of $50-$ $100 \mathrm{~Hz}$ (Hayar et al., 2004b; Liu and Shipley, 2008b). Thus, SACs could receive, and potentially generate, a brief burst of spikes. To simulate bursting input patterns from ETCs, we optically activated SACs in vivo with a train of 5 light pulses with intratrain frequency at $50 \mathrm{~Hz}$ while recording MTC firing. Greater than $70 \%$ of ChR2-positive SACs can follow up to $50 \mathrm{~Hz}$ optical stimulation rates eliciting a spike upon each optical pulse (unpublished data). This burst-patterned IGC activation inhibited MTCs for $468.3 \pm 26.4 \mathrm{~ms}$ with no rebound spiking $(105.6 \pm 10.9 \%$ of prestimulation baseline, $n=14, p>0.05$; Fig. $8 D$ ). 

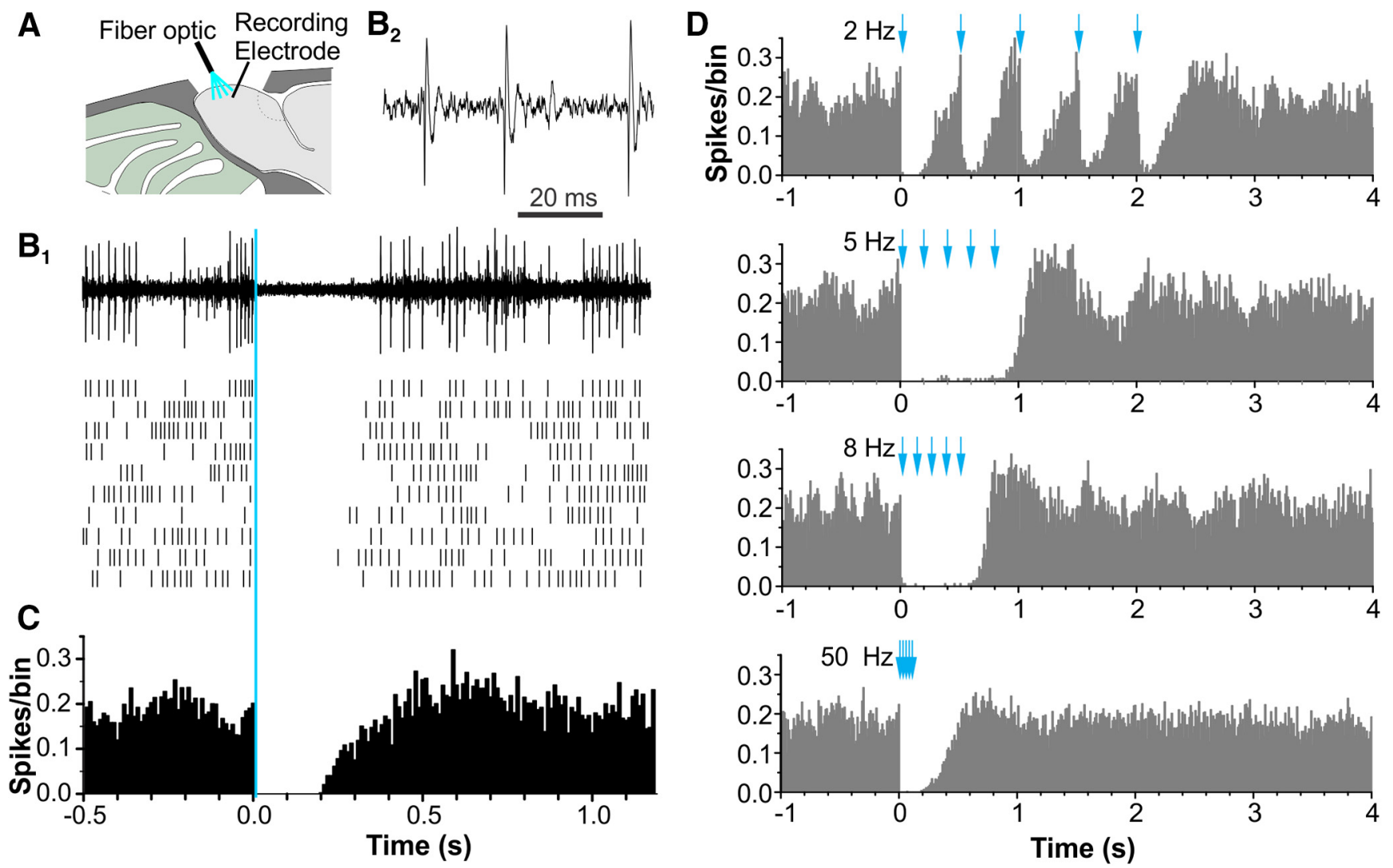

Figure 8. Single or repetitive activation of IGC potently inhibits MTCs in vivo. $A$, Experimental setup of in vivo single-unit recordings of MTCs from TH-Cre mice injected with Cre-inducible ChR2 virus in the $\mathrm{OB} . \boldsymbol{B}_{1}$, Brief optical stimulation of SACs produces prolonged inhibition of MTC spiking. Top, Single trace showing inhibition. Bottom, Raster plots of 10 sweeps at $0.1 \mathrm{~Hz}$. $\boldsymbol{B}_{2}$, Expanded trace from $\boldsymbol{B}_{1}$ showing MTC spontaneous spiking. $\boldsymbol{C}$, Averaged PSTH of 24 recording units from 8 mice showing that single brief optical stimulation consistently produces prolonged inhibition of MTCS. D, Averaged PSTHs of 14 single units from 5 mice showing that a train of 5 brief (blue arrows) optical stimuli at the sniffing frequencies (2-8 Hz) or $50 \mathrm{~Hz}$ (ETC intraburst spiking frequency) produce potent and additive inhibition of MTC firing activity. Bin size: $10 \mathrm{~ms}$.

Together, these in vivo findings show that single or functionally relevant patterns of IGC stimulation all produced inhibition of MTC firing that persisted for hundreds of milliseconds after the termination of IGC stimulation.

\section{Discussion}

Olfactory sensory signals are initially processed in the glomeruli, a complex set of direct and indirect, feedforward and feedback, excitatory and inhibitory, and intraglomerular circuit and IGC. The IGC is a prominent lateral network that impacts the initial site of synaptic integration in the olfactory system. Here, we characterized IGC action on MTCs, the principal OB output neurons, with in vivo and in vitro electrophysiology combined with cell type-specific optogenetics (Fig. $9 A, B$ ) identifying the following: (1) monosynaptic MTC inhibition is mediated by GABA release from SAC $\rightarrow$ MTC synapses; (2) gap junction coupling is strong for SAC $\rightarrow$ MTC synapses but negligible for SAC $\rightarrow$ ETC synapses; (3) brief SAC-MTC inhibition is amplified and temporally prolonged for hundreds of milliseconds by MTC intrinsic properties; (4) IGC-mediated inhibition evokes negligible rebound excitation in MTCs; and (5) IGC stimulation at "sniffing" frequencies above normal respiration produces sustained inhibition of MTCs.

\section{How does the IGC inhibit MTCs?}

At least two indirect pathways can mediate IGC actions on MTCs (Fig. 9B): (1) SAC $\rightarrow$ ETC $\rightarrow$ MTC and (2) SAC $\rightarrow$ ETC $\rightarrow$ PG $\rightarrow$ MTC. Both pathways begin with SAC $\rightarrow$ ETC synapses, which generate a GABA- and DA-mediated sequential inhibition-excitation response in ETCs (Liu et al., 2013). ETCs provide direct excitatory input to MTCs and to PGCs, which inhibit MTCs (Hayar et al., 2004a; De Saint Jan et al., 2009; Shao et al., 2009, 2012, 2013; Gire et al., 2012). Thus, the SAC $\rightarrow$ ETC $\rightarrow$ MTC circuit could decrease ETC $\rightarrow$ MTC excitation, whereas the $\mathrm{SAC} \rightarrow \mathrm{ETC} \rightarrow \mathrm{PG} \rightarrow \mathrm{MTC}$ circuit might reduce ETC $\rightarrow$ PGC inhibitory drive to MTCs resulting in disinhibition (Whitesell et al., 2013; Banerjee et al., 2015). In either circuit, blocking glutamatergic synapses from ETCs to MTCs or PGCs should block the IGC's impact on MTCs. However, we demonstrated that, when both indirect circuits are blocked, there remains a robust direct, monosynaptic, inhibitory connection from SACs to MTCs.

Previous studies reported the absence of a monosynaptic IGC $\rightarrow$ MTC connection (Whitesell et al., 2013; Banerjee et al., 2015). Several factors might account for this. First, we used adult 8- to 12-week-old mice, whereas the Whitesell et al. (2013) recordings were from 12 to 20 postnatal day mice. There could be an age-dependent maturation of the monosynaptic SAC-MTC connection. Consistent with this possibility, Whitesell et al. (2013) reported that stimulation of distal glomeruli evoked NBQX/APV-resistant IPSCs in a minority of MTCs indicating occasional monosynaptic SAC-MTC connection in younger mice. The major difference between our experiments and those of Banerjee et al. (2015) is that they used mice expressing Cre recombinase under transcriptional control of the DA transporter promoter (DAT-cre mice) with $129 \mathrm{~Sv} / \mathrm{J}$ genetic background (Zhuang et al., 2005; Banerjee et al., 2015), whereas we used mice with Cre expression under transcriptional control of the rate lim- 

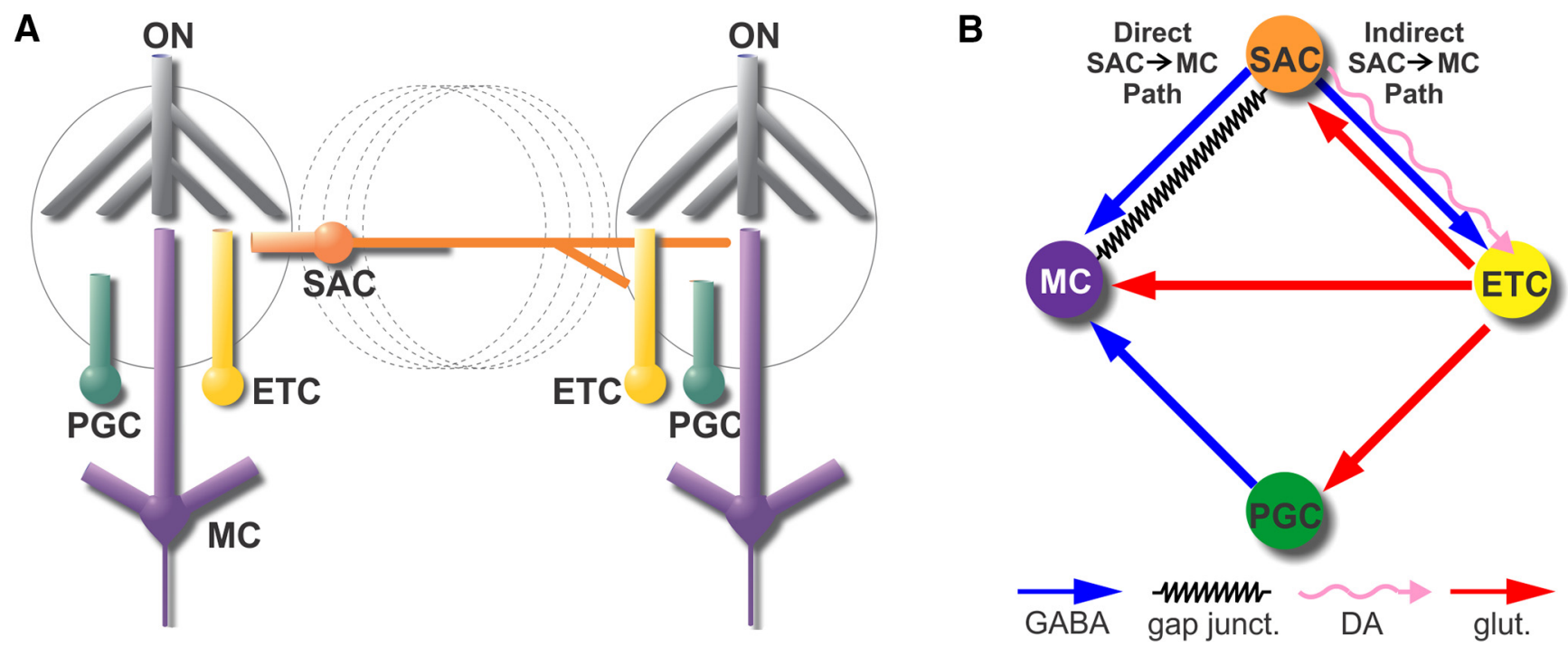

Figure 9. Schematic of mechanisms underlying the IGC impact on OB output. $A$, Simplified illustration of the interglomerular circuit formed by SACs. B, Circuit connection diagram shows the direct and indirect synaptic pathways mediating interglomerular inhibition of MTCs, the principal OB output neurons. gap junct, Gap junction; glut, glutamate.

iting DA synthetic enzyme TH on a C57BL/6N genetic background (Savitt et al., 2005). It is possible that the ChR2 expression in the DAT-Cre mice supports insufficient local membrane depolarization to trigger GABA release or unknown strain differences in the animal's genetic background may play a role. Additional studies are needed to resolve these possibilities, but the present experiments provide unequivocal evidence for a monosynaptic SAC $\rightarrow$ MTC inhibitory synapse.

Although activation of the IGC could suppress ON-evoked responses in MTCs via the $\mathrm{GABA}_{\mathrm{B}}$ and/or DA $\mathrm{D}_{2}$ receptormediated presynaptic inhibition of OSN axon terminals (Berkowicz and Trombley, 2000; Ennis et al., 2001; McGann et al., 2005; Vucinić et al., 2006), the present study showed that the IGC impact on ON-evoked MTC responses is mainly due to postsynaptic action on MTCs: (1) activation of the IGC can terminate MTC responses after an ON stimulation, which can only occur via postsynaptic action; (2) IGC inhibition of MTCs was completely blocked by GBZ, a selective antagonist of $\mathrm{GABA}_{\mathrm{A}}$ receptors, which would have had no effect on any $\mathrm{DA} / \mathrm{GABA}_{\mathrm{B}}$ mediated presynaptic inhibition; and (3) IGC stimulation blocks MTC responses when delivered within a $0-50 \mathrm{~ms}$ time window before an ON stimulation. This unlikely attributes to presynaptic inhibition of MTCs as the G-protein-coupled $\mathrm{GABA}_{\mathrm{B}}$ or $\mathrm{D}_{2}$ receptormediated effects require $\sim 75-100 \mathrm{~ms}$ activation times (McGann et al., 2005; Shao et al., 2009), although presynaptic inhibition may help augment postsynaptic inhibition at greater delay intervals. Together, these results indicate that a major action of the IGC is postsynaptic inhibition of MTC.

\section{MTC intrinsic properties amplify IGC inhibition}

MTCs alternate membrane potential between an up- and downstate (Heyward et al., 2001), driven by a balance between the inward persistent sodium current $\left(\mathrm{I}_{\mathrm{NaP}}\right)$ (Heyward et al., 2001; Hage and Salkoff, 2012) and outward current(s). MTCs have relatively weak hyperpolarization-activated inward currents (Angelo and Margrie, 2011; Angelo et al., 2012) such that their membrane potential returning to upstate is a slow ramp process (Heyward et al., 2001). This is consistent with our demonstration that strong and/or synchronous inhibitory IGC input hyperpo- larizes the MTC membrane potential and generates prolonged $(\sim 400 \mathrm{~ms})$ inhibition of MTCs.

The duration of this inhibition is temporally amplified by MTC intrinsic membrane properties as well as by polysynaptic, indirect circuits. Consequently, the IGC exerts potent, longlasting inhibitory control of MTC output. Thus, circuit-level inhibition is not only a function of presynaptic activity but is also strongly shaped by postsynaptic neuron intrinsic properties.

\section{Electrical transmission in the IGC}

Gap junction-mediated electrical coupling has been reported between MTC apical dendrites (Schoppa and Westbrook, 2002; Christie et al., 2005) and between ETCs (Hayar et al., 2005). Here we demonstrated strong gap junction electrical coupling between SACs and MTCs. After blocking glutamatergic, GABAergic, and DAergic synapses, optical activation of IGC evoked an inward current in MTCs clamped at resting membrane potential. This inward current persisted for the duration of optical stimulation and was abolished by a gap junction blocker. Recently, electrical synapses between SACs and ETCs were reported (Banerjee et al., 2015). However, applying the same paradigm used in that study, we showed that the apparent SAC-ETC electrical coupling was entirely blocked or strongly attenuated by DA receptor antagonists. Moreover, with DA action blocked, the residual electrical coupling between SACs and ETCs was negligible at physiological membrane potentials. We conclude that the putative SAC-ETC gap junction current is due to SAC synaptic release of DA, which increases $I_{h}$ and generates an inward current in ETCs. Together, these findings show that SACs selectively form gap junctions with MTCs but not ETCs.

\section{Functional impact of the IGC}

Unlike visual and auditory stimuli that can be defined by wavelength and amplitude, odor information is encoded by spatiotemporal patterns of glomerular activation (Johnson et al., 1998; Mori et al., 1999; Johnson and Leon, 2007). The pattern of activated glomeruli depends on both the identity and the concentration of the odorant. But the two are potentially confounded: an odorant at a given concentration will activate a pattern of glom- 
eruli, but increased concentration of the same odorant will activate the same and additional glomeruli yet in most cases so that the odor will be perceived as the same but stronger.

The IGC could play a role in disambiguating identity and concentration. The IGCs associated with activated glomeruli would inhibit MTCs in less active glomeruli. Indeed, activation of the IGC positively correlates with odor concentration (Banerjee et al., 2015). This would tend to decrease the sensitivity of MTCs in less active glomeruli and thus could "normalize" output responses to preserve odor identity in the face of increased concentration. As odorant concentration increases, more "off-target" sensory neurons would engage the IGC circuitry in their glomeruli. Because the IGC of weakly activated glomeruli will also inhibit MTCs in more strongly activated ones, IGC circuitry would also counteract response saturation by increased odorant concentration. Thus, the lateral, feedforward inhibition generated by the IGC could sharpen output contrast within the ensemble of activate glomeruli to preserve odor identity as concentration varies (Aungst et al., 2003; Vucinić et al., 2006).

Our findings show that IGC function also has a significant temporal component. When glomeruli are repetitively activated by sniff-like sensory input, the MTC output of less activated glomeruli is truncated by inhibitory IGC input from more strongly activated ones. Moreover, prior activation of the IGC potently suppresses MTC responses in neighboring glomeruli to subsequent sensory activation for hundreds of milliseconds. Glomeruli receiving stronger sensory input are activated slightly earlier than those receiving weaker input (Spors and Grinvald, 2002). The IGC might amplify this temporal activation advantage. At typical resting respiratory rates $(\sim 2 \mathrm{~Hz})$, the impact of preceding IGC activation on MTC responses to subsequent inhalation is modest $(\sim 26 \%)$. However, as sniffing rate increases, prior activation of the IGC more strongly suppresses MTC responses to sensory input. Thus, we propose that, during brief bouts of high-frequency investigative sniffing, only the most strongly activated glomeruli may transfer signals to downstream circuits.

\section{References}

Adrian ED (1950) The electrical activity of the mammalian olfactory bulb. Electroencephalogr Clin Neurophysiol 2:377-388. CrossRef Medline

Angelo K, Margrie TW (2011) Population diversity and function of hyperpolarization-activated current in olfactory bulb mitral cells. Sci Rep 1:50. CrossRef Medline

Angelo K, Rancz EA, Pimentel D, Hundahl C, Hannibal J, Fleischmann A, Pichler B, Margrie TW (2012) A biophysical signature of network affiliation and sensory processing in mitral cells. Nature 488:375-378. CrossRef Medline

Aungst JL, Heyward PM, Puche AC, Karnup SV, Hayar A, Szabo G, Shipley MT (2003) Centre-surround inhibition among olfactory bulb glomeruli. Nature 426:623-629. CrossRef Medline

Baker H, Liu N, Chun HS, Saino S, Berlin R, Volpe B, Son JH (2001) Phenotypic differentiation during migration of dopaminergic progenitor cells to the olfactory bulb. J Neurosci 21:8505-8513. Medline

Banerjee A, Marbach F, Anselmi F, Koh MS, Davis MB, Garcia da Silva P, Delevich K, Oyibo HK, Gupta P, Li B, Albeanu DF (2015) An interglomerular circuit gates glomerular output and implements gain control in the mouse olfactory bulb. Neuron 87:193-207. CrossRef Medline

Beckstead MJ, Grandy DK, Wickman K, Williams JT (2004) Vesicular dopamine release elicits an inhibitory postsynaptic current in midbrain dopamine neurons. Neuron 42:939-946. CrossRef Medline

Belluscio L, Lodovichi C, Feinstein P, Mombaerts P, Katz LC (2002) Odorant receptors instruct functional circuitry in the mouse olfactory bulb. Nature 419:296-300. CrossRef Medline

Berkowicz DA, Trombley PQ (2000) Dopaminergic modulation at the olfactory nerve synapse. Brain Res 855:90-99. CrossRef Medline

Borisovska M, Bensen AL, Chong G, Westbrook GL (2013) Distinct modes of dopamine and GABA release in a dual transmitter neuron. J Neurosci 33:1790-1796. CrossRef Medline

Carlson GC, Shipley MT, Keller A (2000) Long-lasting depolarizations in mitral cells of the rat olfactory bulb. J Neurosci 20:2011-2021. Medline

Christie JM, Bark C, Hormuzdi SG, Helbig I, Monyer H, Westbrook GL (2005) Connexin36 mediates spike synchrony in olfactory bulb glomeruli. Neuron 46:761-772. CrossRef Medline

Crandall SR, Govindaiah G, Cox CL (2010) Low-threshold $\mathrm{Ca}^{2+}$ current amplifies distal dendritic signaling in thalamic reticular neurons. J Neurosci 30:15419-15429. CrossRef Medline

De Saint Jan D, Hirnet D, Westbrook GL, Charpak S (2009) External tufted cells drive the output of olfactory bulb glomeruli. J Neurosci 29:20432052. CrossRef Medline

Dumenieu M, Fourcaud-Trocme N, Garcia S, Kuczewski N (2015) Afterhyperpolarization (AHP) regulates the frequency and timing of action potentials in the mitral cells of the olfactory bulb: role of olfactory experience. Physiol Rep 3:5. CrossRef Medline

Ennis M, Zhou FM, Ciombor KJ, Aroniadou-Anderjaska V, Hayar A, Borrelli E, Zimmer LA, Margolis F, Shipley MT (2001) Dopamine D2 receptormediated presynaptic inhibition of olfactory nerve terminals. J Neurophysiol 86:2986-2997. Medline

Gire DH, Franks KM, Zak JD, Tanaka KF, Whitesell JD, Mulligan AA, Hen R, Schoppa NE (2012) Mitral cells in the olfactory bulb are mainly excited through a multistep signaling path. J Neurosci 32:2964-2975. CrossRef Medline

Govindaiah G, Cox CL (2005) Excitatory actions of dopamine via D1-like receptors in the rat lateral geniculate nucleus. J Neurophysiol 94:37083718. CrossRef Medline

Hage TA, Salkoff L (2012) Sodium-activated potassium channels are functionally coupled to persistent sodium currents. J Neurosci 32:2714-2721. CrossRef Medline

Hayar A, Shipley MT, Ennis M (2005) Olfactory bulb external tufted cells are synchronized by multiple intraglomerular mechanisms. J Neurosci 25:8197-8208. CrossRef Medline

Hayar A, Karnup S, Ennis M, Shipley MT (2004a) External tufted cells: a major excitatory element that coordinates glomerular activity. J Neurosci 24:6676-6685. CrossRef Medline

Hayar A, Karnup S, Shipley MT, Ennis M (2004b) Olfactory bulb glomeruli: external tufted cells intrinsically burst at theta frequency and are entrained by patterned olfactory input. J Neurosci 24:1190-1199. CrossRef Medline

Heckman CJ, Hyngstrom AS, Johnson MD (2008) Active properties of motoneurone dendrites: diffuse descending neuromodulation, focused local inhibition. J Physiol 586:1225-1231. CrossRef Medline

Heyward P, Ennis M, Keller A, Shipley MT (2001) Membrane bistability in olfactory bulb mitral cells. J Neurosci 21:5311-5320. Medline

Hong EJ, Wilson RI (2015) Simultaneous encoding of odors by channels with diverse sensitivity to inhibition. Neuron 85:573-589. CrossRef Medline

Hultborn H, Brownstone RB, Toth TI, Gossard JP (2004) Key mechanisms for setting the input-output gain across the motoneuron pool. Prog Brain Res 143:77-95. Medline

Johnson BA, Woo CC, Leon M (1998) Spatial coding of odorant features in the glomerular layer of the rat olfactory bulb. J Comp Neurol 393: 457-471. CrossRef Medline

Johnson BA, Leon M (2007) Chemotopic odorant coding in a mammalian olfactory system. J Comp Neurol 503:1-34. CrossRef Medline

Johnston J, Delaney KR (2010) Synaptic activation of T-type $\mathrm{Ca}^{2+}$ channels via mGluR activation in the primary dendrite of mitral cells. J Neurophysiol 103:2557-2569. CrossRef Medline

Jones DT, Reed RR (1989) Golf: an olfactory neuron specific-G protein involved in odorant signal transduction. Science 244:790-795. CrossRef Medline

Kiyokage E, Pan YZ, Shao Z, Kobayashi K, Szabo G, Yanagawa Y, Obata K, Okano H, Toida K, Puche AC, Shipley MT (2010) Molecular identity of periglomerular and short axon cells. J Neurosci 30:1185-1196. CrossRef Medline

Kosaka T, Kosaka K (2008) Tyrosine hydroxylase-positive GABAergic juxtaglomerular neurons are the main source of the interglomerular connections in the mouse main olfactory bulb. Neurosci Res 60:349-354. CrossRef Medline

Liu S, Shipley MT (2008a) Intrinsic conductances actively shape excitatory 
and inhibitory postsynaptic responses in olfactory bulb external tufted cells. J Neurosci 28:10311-10322. CrossRef Medline

Liu S, Shipley MT (2008b) Multiple conductances cooperatively regulate spontaneous bursting in mouse olfactory bulb external tufted cells. J Neurosci 28:1625-1639. CrossRef Medline

Liu S, Aungst JL, Puche AC, Shipley MT (2012) Serotonin modulates the population activity profile of olfactory bulb external tufted cells. J Neurophysiol 107:473-483. CrossRef Medline

Liu S, Plachez C, Shao Z, Puche A, Shipley MT (2013) Olfactory bulb short axon cell release of GABA and dopamine produces a temporally biphasic inhibition-excitation response in external tufted cells. J Neurosci 33: 2916-2926. CrossRef Medline

Liu S, Shao Z, Puche A, Wachowiak M, Rothermel M, Shipley MT (2015) Muscarinic receptors modulate dendrodendritic inhibitory synapses to sculpt glomerular output. J Neurosci 35:5680-5692. CrossRef Medline

McGann JP, Pírez N, Gainey MA, Muratore C, Elias AS, Wachowiak M (2005) Odorant representations are modulated by intra- but not interglomerular presynaptic inhibition of olfactory sensory neurons. Neuron 48:1039-1053. CrossRef Medline

Mombaerts P, Wang F, Dulac C, Chao SK, Nemes A, Mendelsohn M, Edmondson J, Axel R (1996) Visualizing an olfactory sensory map. Cell 87:675-686. CrossRef Medline

Mori K, Nagao H, Yoshihara Y (1999) The olfactory bulb: coding and processing of odor molecule information. Science 286:711-715. CrossRef Medline

Najac M, De Saint Jan D, Reguero L, Grandes P, Charpak S (2011) Monosynaptic and polysynaptic feed-forward inputs to mitral cells from olfactory sensory neurons. J Neurosci 31:8722-8729. CrossRef Medline

Ressler KJ, Sullivan SL, Buck LB (1994) Information coding in the olfactory system: evidence for a stereotyped and highly organized epitope map in the olfactory bulb. Cell 79:1245-1255. CrossRef Medline

Saino-Saito S, Sasaki H, Volpe BT, Kobayashi K, Berlin R, Baker H (2004) Differentiation of the dopaminergic phenotype in the olfactory system of neonatal and adult mice. J Comp Neurol 479:389-398. CrossRef Medline

Savitt JM, Jang SS, Mu W, Dawson VL, Dawson TM (2005) Bcl-x is required for proper development of the mouse substantia nigra. J Neurosci 25: 6721-6728. CrossRef Medline

Schoppa NE, Westbrook GL (2002) AMPA autoreceptors drive correlated spiking in olfactory bulb glomeruli. Nat Neurosci 5:1194-1202. CrossRef Medline

Shao Z, Puche AC, Kiyokage E, Szabo G, Shipley MT (2009) Two GABAergic intraglomerular circuits differentially regulate tonic and phasic pre- synaptic inhibition of olfactory nerve terminals. J Neurophysiol 101: 1988-2001. CrossRef Medline

Shao Z, Puche AC, Liu S, Shipley MT (2012) Intraglomerular inhibition shapes the strength and temporal structure of glomerular output. J Neurophysiol 108:782-793. CrossRef Medline

Shao Z, Puche AC, Shipley MT (2013) Intraglomerular inhibition maintains mitral cell response contrast across input frequencies. J Neurophysiol 110:2185-2191. CrossRef Medline

Shirley CH, Coddington EJ, Heyward PM (2010) All-or-none population bursts temporally constrain surround inhibition between mouse olfactory glomeruli. Brain Res Bull 81:406-415. CrossRef Medline

Solinas SM, Maex R, De Schutter E (2006) Dendritic amplification of inhibitory postsynaptic potentials in a model Purkinje cell. Eur J Neurosci 23:1207-1218. CrossRef Medline

Spors H, Grinvald A (2002) Spatio-temporal dynamics of odor representations in the mammalian olfactory bulb. Neuron 34:301-315. CrossRef Medline

Stuart G, Sakmann B (1995) Amplification of EPSPs by axosomatic sodium channels in neocortical pyramidal neurons. Neuron 15:1065-1076. CrossRef Medline

Tsai HC, Zhang F, Adamantidis A, Stuber GD, Bonci A, de Lecea L, Deisseroth K (2009) Phasic firing in dopaminergic neurons is sufficient for behavioral conditioning. Science 324:1080-1084. CrossRef Medline

Vassar R, Chao SK, Sitcheran R, Nuñez JM, Vosshall LB, Axel R (1994) Topographic organization of sensory projections to the olfactory bulb. Cell 79:981-991. CrossRef Medline

Verhagen JV, Wesson DW, Netoff TI, White JA, Wachowiak M (2007) Sniffing controls an adaptive filter of sensory input to the olfactory bulb. Nat Neurosci 10:631-639. CrossRef Medline

Vucinić D, Cohen LB, Kosmidis EK (2006) Interglomerular centersurround inhibition shapes odorant-evoked input to the mouse olfactory bulb in vivo. J Neurophysiol 95:1881-1887. CrossRef Medline

Whitesell JD, Sorensen KA, Jarvie BC, Hentges ST, Schoppa NE (2013) Interglomerular lateral inhibition targeted on external tufted cells in the olfactory bulb. J Neurosci 33:1552-1563. CrossRef Medline

Williams SR, Stuart GJ (2003) Voltage- and site-dependent control of the somatic impact of dendritic IPSPs. J Neurosci 23:7358-7367. Medline

Zhan X, Yin P, Heinbockel T (2013) The basal forebrain modulates spontaneous activity of principal cells in the main olfactory bulb of anesthetized mice. Front Neural Circuits 7:148. CrossRef Medline

Zhuang X, Masson J, Gingrich JA, Rayport S, Hen R (2005) Targeted gene expression in dopamine and serotonin neurons of the mouse brain. J Neurosci Methods 143:27-32. CrossRef Medline 